\title{
Application of cyclic phosphonamide reagents in the total synthesis of natural products and biologically active molecules
}

Thilo Focken ${ }^{1}$ and Stephen Hanessian ${ }^{* 2}$

\author{
Review \\ Address: \\ ${ }^{1}$ Xenon Pharmaceuticals Inc., 3650 Gilmore Way, Burnaby, BC V5G \\ 4W8, Canada and ${ }^{2}$ Department of Chemistry, Université de Montréal, \\ C.P. 6128, Succursale Centre-Ville, Montréal, QC H3C 3J7, Canada \\ Email: \\ Stephen Hanessian * - stephen.hanessian@umontreal.ca \\ * Corresponding author \\ Keywords: \\ conjugate addition; cyclopropanation; olefination; organophosphorus; \\ phosphonamide; total synthesis
}

Beilstein J. Org. Chem. 2014, 10, 1848-1877.

doi:10.3762/bjoc. 10.195

Received: 10 April 2014

Accepted: 26 June 2014

Published: 13 August 2014

This article is part of the Thematic Series "Organophosphorus chemistry".

Guest Editor: P. R. Hanson

(c) 2014 Focken and Hanessian; licensee Beilstein-Institut. License and terms: see end of document.

\section{Abstract}

A review of the synthesis of natural products and bioactive compounds adopting phosphonamide anion technology is presented highlighting the utility of phosphonamide reagents in stereocontrolled bond-forming reactions. Methodologies utilizing phosphonamide anions in asymmetric alkylations, Michael additions, olefinations, and cyclopropanations will be summarized, as well as an overview of the synthesis of the employed phosphonamide reagents.

\section{Introduction}

Chiral non-racemic and achiral cyclic phosphonamide reagents 1-7 (Figure 1) have been employed in organic synthesis primarily as stabilized anionic nucleophiles in addition reactions to electrophilic substrates with good to excellent stereocontrol. The products obtained from these reactions were used as key building blocks in the total synthesis of a variety of structurally highly diverse and complex natural products and also of biologically active compounds.

The phosphonamide anions are derived from a small number of common motifs as shown in Figure 1. Diazaphospholidine 2 was introduced by Hanessian and co-workers, and represents the most commonly used phosphonamide in organic synthetic

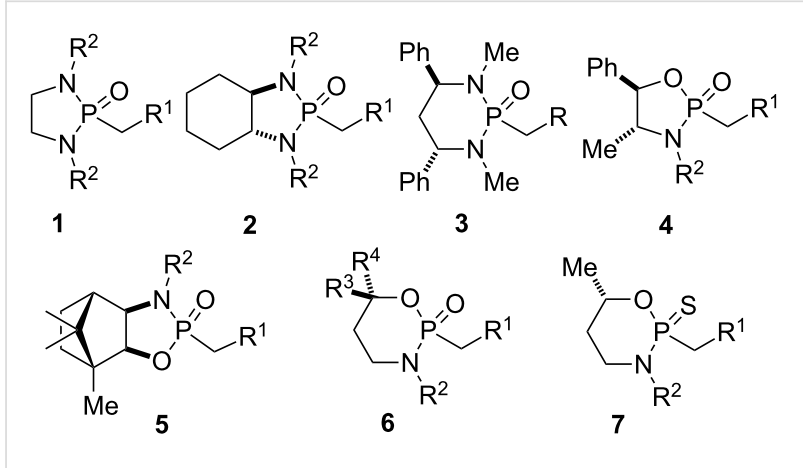

Figure 1: Examples of phosphonamide reagents used in stereoselective synthesis. 
transformations [1]. This chiral phosphonamide typically yields reaction products with excellent stereocontrol, which are easily isolated as diastereometrically pure or highly enriched compounds. Many are crystalline solids that can be purified further by recrystallization. Diazaphosphorinane 3 and oxazaphosphorinanes 6 and 7 have been extensively studied by Denmark and co-workers [2-4]. Oxazaphospholidine 4 was independently developed by Hua [5,6], Steglich [7] and their respective co-workers. Camphor oxazaphospholidine $\mathbf{5}$ was reported by Sisti and co-workers $[8,9]$.

This review focuses on the application of phosphonamide reagents in the total synthesis of natural products and biologically active compounds. An overview of the molecules synthesized by phosphonamide technology is shown in Figure 2. Each molecule shown will be discussed in detail later in this review. First, relevant methodologies utilizing phosphonamides will be discussed, followed by an overview of synthetic routes for the preparation of phosphonamide reagents.

\section{Review}

\section{Phosphonamides in stereoselective} synthesis

For the purpose of this review, only phosphonamide methodologies with applications in the synthesis of natural products or bioactive molecules will be discussed [10]. Similar technologies to the ones discussed here without such applications and other uses of chiral phosphonamide reagents in asymmetric synthesis such as Denmark's carbanion-accelerated Claisen rearrangements $[11,12]$ have been reviewed elsewhere $[13,14]$. These methodologies will be mentioned where appropriate but not discussed in detail.

\section{Olefination}

Monocyclic phosphonamide reagents of type 1 bearing a $N, N$ 'dialkylethane-1,2-diamine backbone were first reported as olefination reagents by Corey and Cane [15] and later by Savignac [16,17], and Hanessian [18] and their co-workers. Deprotonation of phosphonamides of type $\mathbf{1}$ affords weakly basic anions<smiles>CC(=O)CCC=C(C)CCC1C(C=O)C1(C)C</smiles>

anthoplalone (8)<smiles>C/C=C1/C(CC(=O)OC[C@H]2[C@@H](O)C[C@@H](O)[C@H]2C(C)CO)C(C(=O)OC)=CO[C@@H]1OC</smiles><smiles>C/C=C1/CNC1C(=O)O</smiles>

polyoximic acid (9)

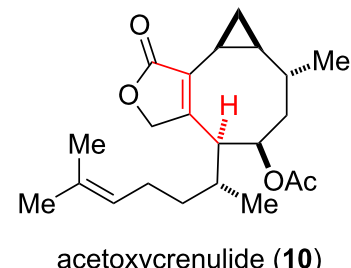

acetoxycrenulide (10)<smiles>CC/C=C\C[C@H]1C(=O)CCC1CC(C)=O</smiles>

methyl jasmonate (11)<smiles>CC12CC[C@H]3c4ccc(O)cc4CC[C@H]3[C@@H]1CCC2=O</smiles>

estrone (12)

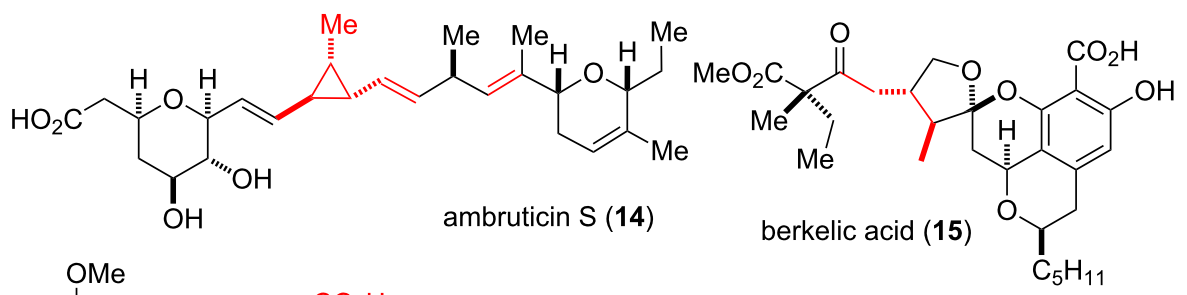<smiles>O=P(O)(O)c1cccc(-c2ccccc2)c1</smiles>

protein tyrosine phosphatase inhibitor (16)<smiles>CS(=O)(=O)N1C(COc2cccnc2)C1C(=O)NO</smiles>

MMP inhibitor (17)<smiles>NC(C(=O)O)C1C(C(=O)O)C1C(=O)O</smiles><smiles>N[C@H](C(=O)O)C1C(PO)[C@@H]1c1ccccc1</smiles><smiles>[Z6]OS(=O)(=O)C(CCCc1cccc(Oc2ccccc2)c1)P(=O)([O-])[Co]</smiles>
mGluR agonist (21)<smiles>CCCCCCCCCCCCCCCCCCC(=O)O</smiles><smiles>CCC1OC(/C(C)=C/C(C)/C=C/[C@@H]2CC(OC)=C(CO)C(=O)O2)CC=C1C</smiles><smiles>CC(O)C1C(=O)N2C(C(=O)O)=C3C[C@H](CCO)CC[C@H]3[C@H]12</smiles>

Figure 2: Natural products and bioactive molecules synthesized using phosphonamide-based chemistry (atoms, bonds and stereocenters formed by phosphonamide reagents are highlighted in red). 
which are excellent reagents for the transformation of aldehydes and ketones into the corresponding alkenes 27 via intermediates 25 and $\mathbf{2 6}$ (Scheme 1) [18]. Contrary to their acyclic $\mathrm{N}, \mathrm{N}$-diethyl phosphonamides, which require harsher conditions to undergo fragmentation [19], cyclic oxaphosphetane oxide 26 releases the corresponding olefin 27 upon treatment with cold acetic acid [18]. Moreover, the only weakly basic nature of the "soft" phosphonamide anion favors the attack on the carbonyl group over enolization. Thus, treatment of $\Delta 5$-cholestenone with 24a yielded the unconjugated olefin 27a in addition to recovered unreacted enone, whereas phosphorus ylides would form $\Delta 4$-cholestenone via enolization and double bond conjugation [20].

Other monocyclic phosphonamides with application in olefination reactions are those derived from 1-(tert-butylamino)-2- methylpropan-2-ol. Denmark and Amburgey used this type of phosphonamides in a four-step protocol for the highly stereoselective synthesis of trisubstituted alkenes [21].

The application of cyclic phosphonamides was further extended toward asymmetric olefination reactions by Hanessian and co-workers, using a chiral, non-racemic diamine to generate the corresponding olefination reagents $[1,22,23]$. To this end the $C_{2}$-symmetric phosphonamide $(R, R)-\mathbf{2 8}$ derived from trans$(R, R)$ - $N, N$ '-dimethyl-1,2-diaminocyclohexane [14] was conceived of as a chiral version of $N, N^{\prime}$-dialkylethane-1,2-diamine phosphonamide 24 (Scheme 1 and Scheme 2). The reaction of anions 29 with ketones leads to the corresponding $\beta$-hydroxy phosphonamide intermediates 30, which undergo elimination of the intermediate oxaphosphetanes to give chiral olefins 31 with moderate to high enantioselectivities. The attack

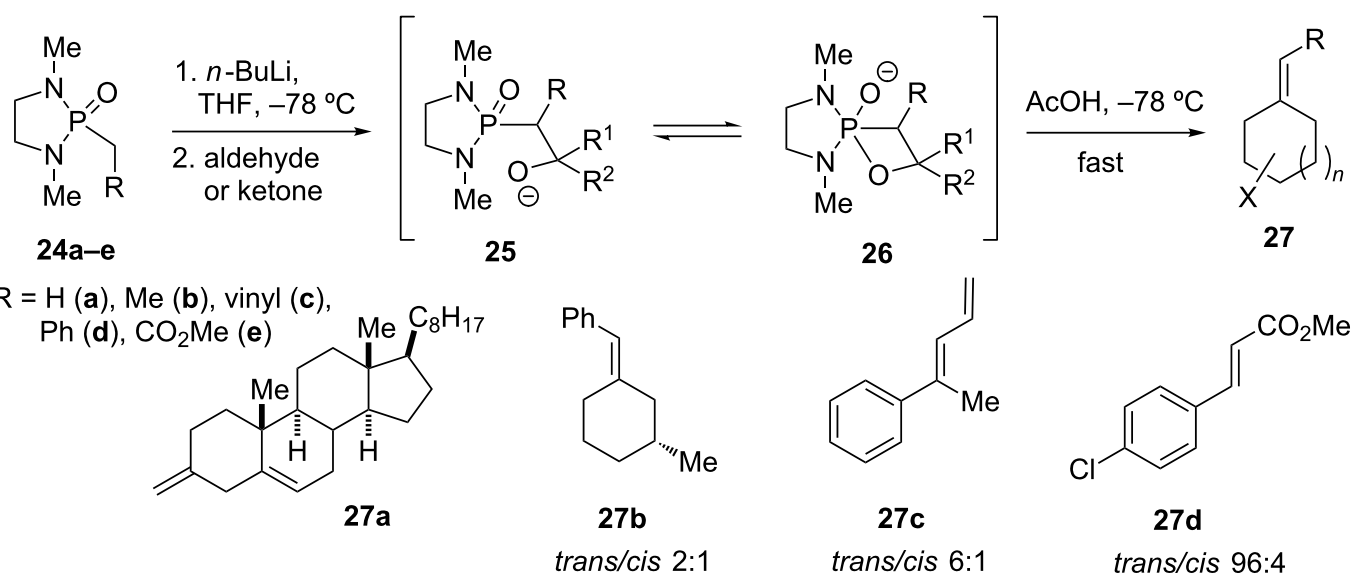

Scheme 1: Olefination with cyclic phosphonamide anions, mechanistic rationale, and selected examples 27a-d [18].

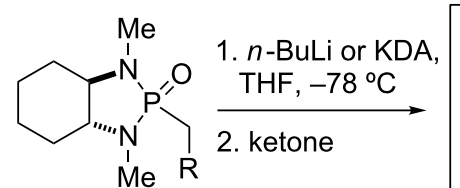

$(R, R)-28 \mathrm{a}-\mathrm{c}$

$\mathrm{R}=\mathrm{Me}(\mathbf{a}), \mathrm{Ph}(\mathbf{b}), \operatorname{vinyl}(\mathbf{c})$<smiles>[10B]C1CCC(=CC)CC1</smiles>

$31 \mathrm{a}$

$90 \%$ ee

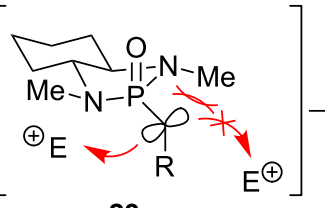

29

favored "left cleft" enantiofacial approach

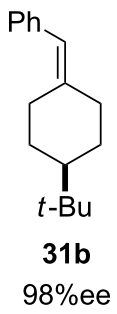

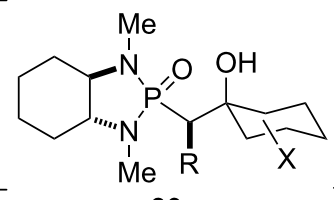

30

trans/cis 96:4 
of electrophiles E is favored from the "left cleft" of the anion 29 in the $(R, R)$-isomer due to steric and stereoelectronic effects. Intermediates such as $\mathbf{3 0}$ can be isolated and purified as crystalline solids suitable for X-ray analysis if water is used for quenching instead of acetic acid.

Olefinations based on phosphonamides were employed in the construction of di- and trisubstituted double bonds in the total synthesis of polyoximic acid [24-26], jerangolid A [27], and ambruticin S [28], as discussed later in this review.

\section{Alkylations and aminations}

Treatment of $\alpha$-phosphoryl carbanions with alkyl halides gives stereoselective access to a variety of $\alpha$-substituted alkylphosphonic acids (Scheme 3). The attack on the alkyl halide occurs from the "left cleft" side of the anion 29 in the $(R, R)$-isomer. Thus, $\alpha$-substituted phosphonamides $\mathbf{3 2}$ can be obtained in good to excellent diastereoselectivity and further hydrolyzed to the corresponding enantiomerically pure $\alpha$-substituted phosphonic acids $33[22,29,30]$. Other asymmetric alkylation methodologies using chiral phosphonamides were reported by the groups of Denmark [3,4] and Steglich [7].

Remarkably, the alkylation of $\alpha$-dithioalkylimino phosphonamide 28e provided a diastereomer of $\mathbf{3 2}$ with the opposite configuration of the newly formed stereocenter. This inversion in asymmetric induction relative to non-heteroatom substituted phosphonamides such as 28a is presumably a result of a chelated intermediate that exposes the opposite face of the anion to the electrophile compared to the conventionally accepted model [31]. The use of other electrophiles for the stereoselective formation of $\mathrm{C}-\mathrm{N}$ bonds has also been reported. Thus, $\alpha$-amino- $\alpha$-alkyl phosphonic acids [32-34] could be obtained through amination and azidation of phosphonamide anions, respectively, and subsequent conversion of the primary adducts [35]. The enantioselective synthesis of $\alpha$-phosphonosulfonic acids as squalene inhibitors, as discussed later in this review, was achieved using similar reactions - asymmetric alkylation of an $\alpha$-sulfo phosphonamide and asymmetric $\alpha$-sulfuration of an $\alpha$-alkyl phosphonamide, respectively [36].

\section{Michael reactions}

The application of chiral, cyclic phosphonamides such as $\mathbf{2 8 c}$ in asymmetric Michael-type reactions has proven to be a powerful tool in natural product synthesis to generate up to three contiguous stereogenic centers in a single step with a high level of stereocontrol (Scheme 4) [37-40]. Thus, vicinal and quartenary carbon centers can be obtained in high diasteromeric purity by conjugate additions of allyl, crotyl, and cinnamyl-derived anions to Michael acceptors such as enones, lactones, lactams, and $\alpha, \beta$-unsaturated esters followed by optional alkylation to give adducts 35 . The stereoselectivity of the reaction can be explained by lithium-coordinated intermediate $\mathbf{3 8}$, in which chelated Michael acceptors are best accommodated within the "left-cleft" of the $(R, R)$-reagents $\mathbf{2 8 c}$ and $\mathbf{2 8 f}, \mathbf{g}$. The resulting vinyl phosphonamide product bearing the chiral auxiliary can be cleaved by ozonolysis to the corresponding aldehydes $\mathbf{3 6}$ and the latter reduced to alcohols 37, respectively, as shown in Scheme 4. Many highly functionalized, vicinally substituted compounds could be prepared by this method in good to excellent enantiopurity [37-40].

Asymmetric conjugate additions using $P$-chiral phosphonamides were reported by Denmark [2-4] and Hua [5,6], with remarkable differences in selectivity depending on the configuration of the $P$-stereogenic center (Scheme 5). Thus, the addition of the Li-anion of trans-40a to cyclic enones 41 proceeded with a high level of stereocontrol, providing adducts $\mathbf{4 2}$ with up 


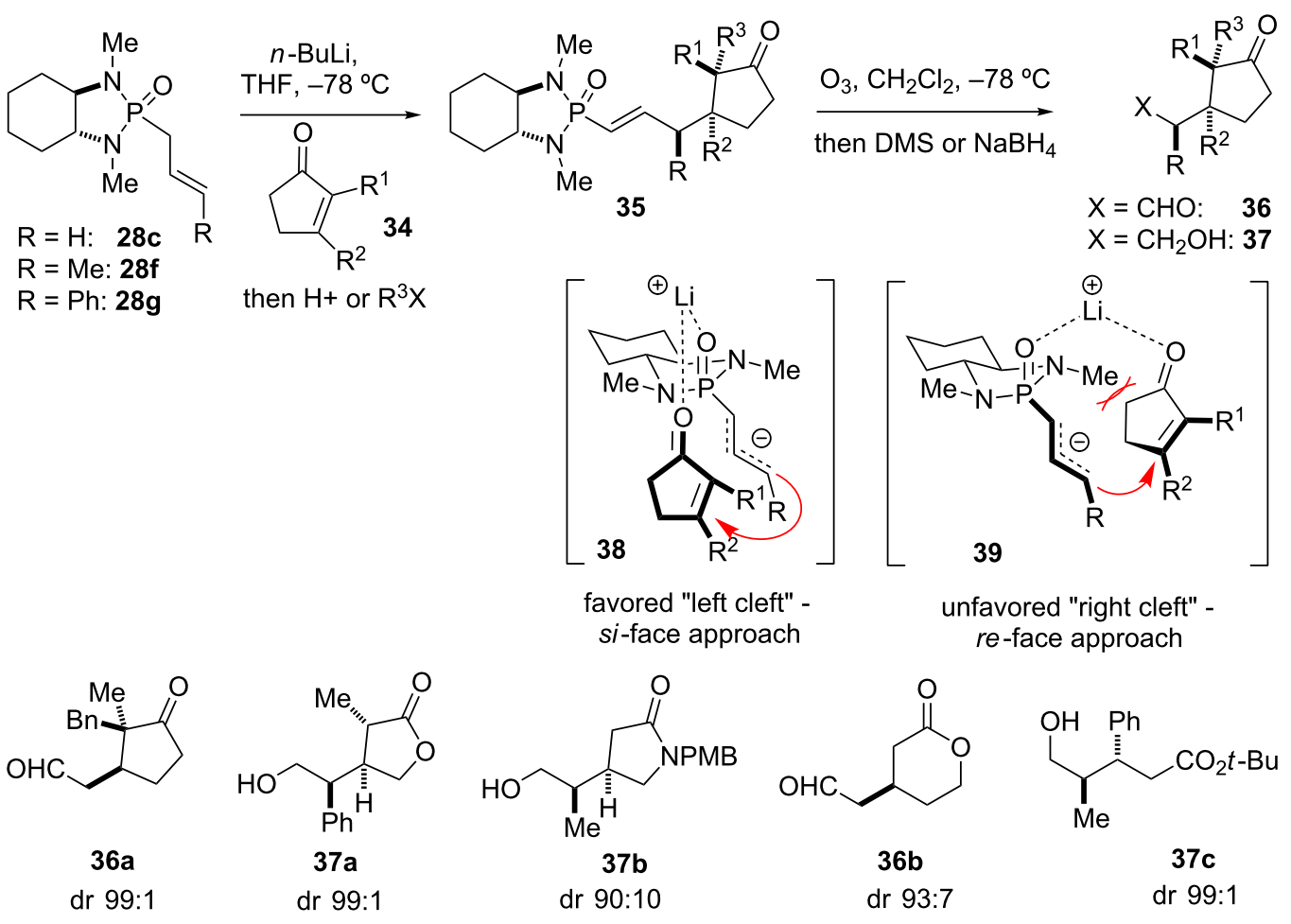

Scheme 4: Asymmetric conjugate additions of $C_{2}$-symmetric chiral phosphonamide anions to cyclic enones, lactones, lactams, and $\alpha, \beta$-unsaturated esters with optional enolate alkylations; mechanistic rationale, and selected examples $\mathbf{3 6}$ and $\mathbf{3 7}$ after cleavage of the auxiliary. Diastereomeric ratios (dr) refer to the corresponding phosphonamide adducts 35 before ozonolysis-reduction [37-40].

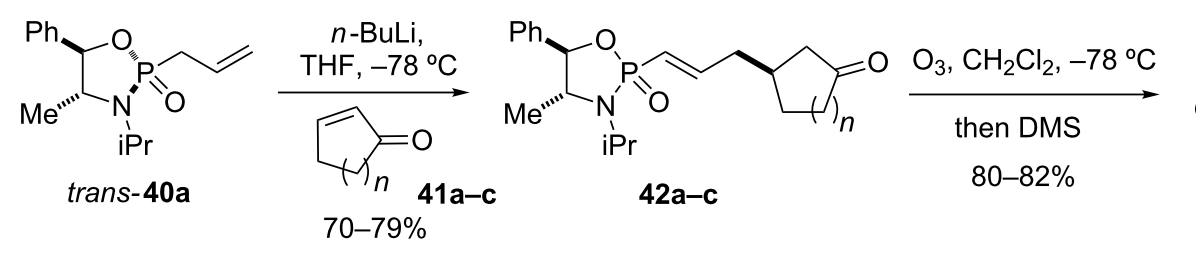<smiles>CC1CC(=O)CC1CC=O</smiles>

$n=1: 43 a, 98 \%$ ee $n=2: 43 \mathrm{~b}, 88 \%$ ee $n=3: 43 c, 95 \%$ ee

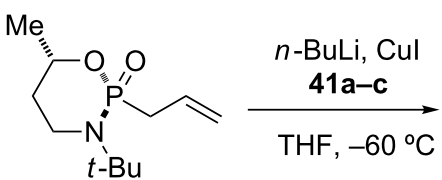

$41-78 \%$<smiles>CC1CCN(C)P(=O)(/C=C/C[C@H]2CC(=O)CC2=O)O1</smiles>
$t$-Bu

$45 a-c$

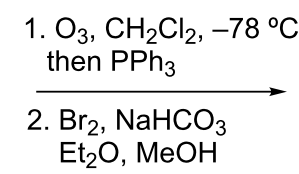
$59-72 \%$<smiles>CC(=O)C[C@H]1CCC(=O)C1</smiles>

$n=1: 46 \mathbf{a}, 89 \%$ ee $n=2: \mathbf{4 6 b}, 87 \%$ ee $n=3: 46 c, 89 \%$ ee<smiles>C=CCP1(=O)OC(c2ccccc2)[C@@H](C)N1C(C)C</smiles>

cis-40b<smiles>C=CCP1(=O)OC(C)CCN1C(C)(C)C</smiles>

trans-44b

Scheme 5: Asymmetric conjugate additions of $P$-chiral phosphonamide anions generated from 40 a and $44 a$ to cyclic enones, and further derivatization of the adducts [2-6].

to $98 \%$ ee. Cis and trans refer to the orientation of the $P$-alkyl group relative to the $N$-alkyl group, in agreement with Denmark's naming of oxazaphosphorinanes [2-4]. Thus, trans describes a compound with a $S$-configurated phosphorus center, whereas cis confers to a $R$-configuration. Degradation of the adducts by ozonolysis yielded oxocycloalkane-3-carboxalde- 
hydes $\mathbf{4 3}$, which are useful synthetic intermediates. Diastereomer cis-40b however gave only poor diastereofacial selection, providing the corresponding 1,4-addition adducts in $28-64 \%$ ee [5]. In a similar fashion, Denmark's oxazaphosphorinane cis44a yielded keto esters 46a-c in high optical purities via conjugate addition to enones $\mathbf{4 1}$ followed by ozonolysis and oxidative esterification. Using diastereomer trans-44b on the other hand provided ketoesters $46 \mathbf{a}-\mathbf{c}$ with only $10-15 \%$ ee [2].

Asymmetric Michael additions using phosphonamides 28c,f, or analogs of $\mathbf{2 8}$ and $\mathbf{4 0}$, respectively, were applied in the total synthesis of acetoxycrenulide (10) [41,42], berkelic acid (15) [43], estrone (12) [44], fumonisin $B_{2}$ (20) [45-47], methyl jasmonate (11) [48], and nudifloside A and D (13) [49], as discussed later in this review. Studies for the synthesis of the polyphenolic natural products tatanans $\mathrm{A}-\mathrm{C}$ also explored the use of phosphonamide technology [50]. The discussion of the latter natural products is not included in this review, as phosphonamide technology was only used for limited exploratory studies.

\section{Cyclopropanation and aziridination}

The cyclopropanation of $\alpha, \beta$-unsaturated esters and lactones using chiral phosphonamide reagents is a special case of the conjugate addition-enolate alkylation sequence. The application of chloroallyl phosphonamides such as (trans, $R, R)-\mathbf{4 7 a}$ in the conjugate addition to enones provides the corresponding fused endo,endo-cyclopropane 50a in high diastereomeric excess [51]. The transformation proceeds via the intermediate Michael adduct 49, which eliminates chloride after stereocontrolled attack of the enolate to afford cyclopropane 50a. Starting with $($ cis $, R, R)-\mathbf{4 7} \mathbf{b}$, the isomeric exo,endo product 50b is obtained as major isomer. The cyclopropanation reaction tolerates a wide range of Michael acceptor subtrates such as enones, lactones, lactams, and acyclic $\alpha, \beta$-unsaturated esters. The obtained products can easily be cleaved to the corresponding aldehydes 51 by ozonolysis, reduced further to alcohols 52, and constitute versatile cyclopropane chirons (Scheme 6) [51-55].

The cyclopropanation with chloroallyl phosphonamide 47a was used to construct the cyclopropane fragments of anthoplalone (8) [56], ambruticin S (14) [28], and mGluR agonist DCG-IV (18) [57], as discussed later in this review. Studies for the synthesis of ottelione A and B [58] also employed this cyclopropanation methodology using a mixture of $47 \mathbf{a}$ and $47 \mathbf{b}$. The discussion of the latter natural products is not included in this review, as phosphonamide technology was only used for limited exploratory studies.

Replacing chloroallyl phosphonamides 47 with chloromethyl phosphonamide $\mathbf{2 8 d}$ in the addition to $\alpha, \beta$-unsaturated esters also gives cyclopropane products, which can be converted to cyclopropylphosphonic acids $\mathbf{5 4}$ and aminocyclopropylphosphonic acids 55 (Scheme 7) [59]. The synthesis of an mGluR<smiles>CC1=C[C+](Cl)CC1=O</smiles><smiles>CN1C2CCCC[C@H]2N(C)P1(=O)C/C=C\Cl</smiles><smiles>[10BH2][10BH2-]</smiles>

$(c i s, R, R)-47 \mathrm{~b}$

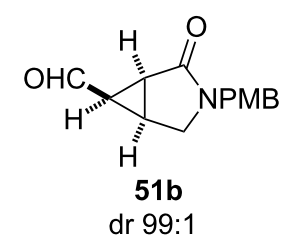

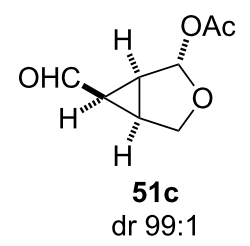

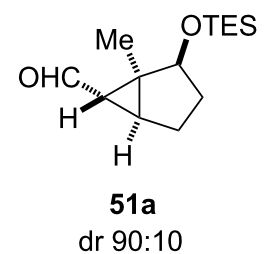

$70 \%, \mathrm{dr}>90: 10$

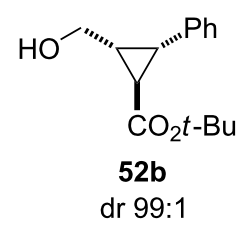

Scheme 6: Asymmetric cyclopropanation with chiral chloroallyl phosphonamide 47, mechanistic rationale, and selected examples 51 and 52 after cleavage of the auxiliary and further derivatization. Diastereomeric ratios (dr) refer to the corresponding phosphonamide adducts $\mathbf{5 0}$ before ozonolysis-reduction [51]. 


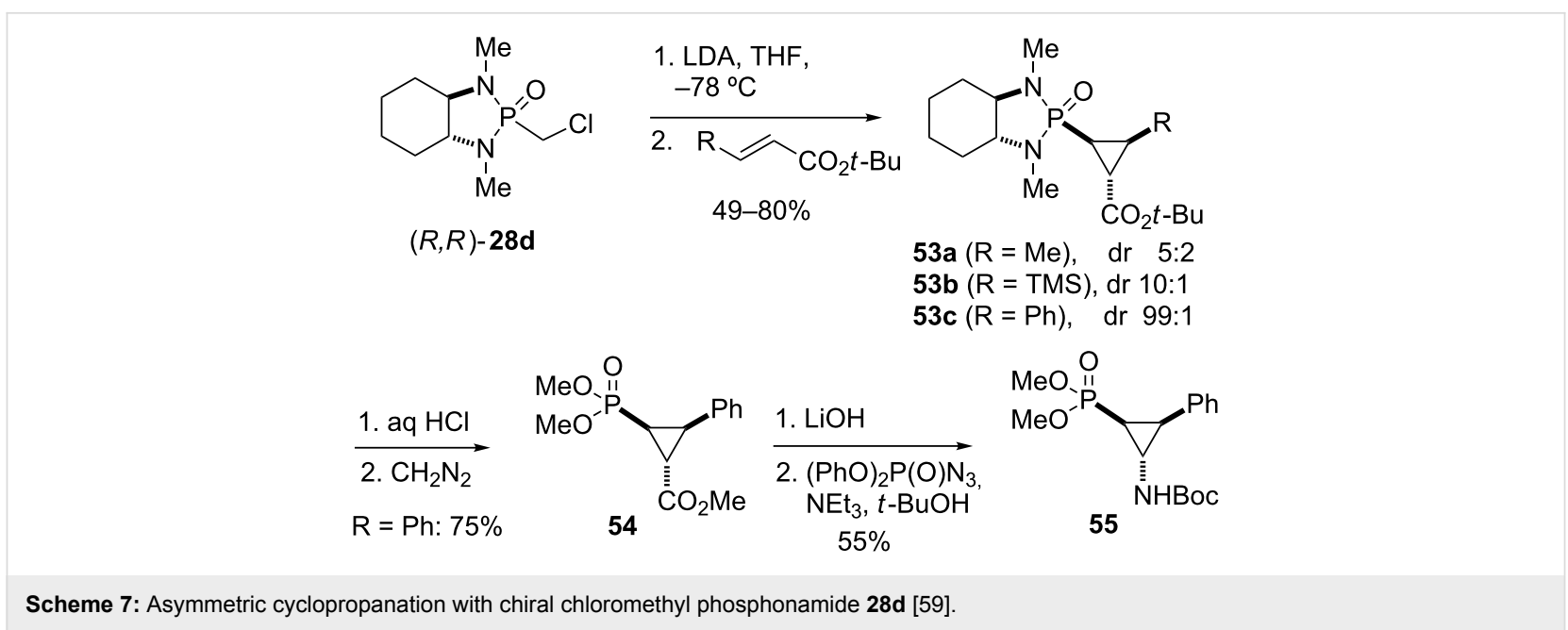

agonist was achieved using chloromethyl phosphonamide 28d $[60,61]$, as discussed later in this review.

Replacing Michael acceptors with oximes in the reaction with chloroallyl phosphonamide 47 a leads to the stereoselective formation of cis-aziridines 57 (Scheme 8) [62]. Thus, addition of the anion of phosphonamide 47 a to tert-butyl glyoxylate $O$-protected oximes affords the corresponding aziridine adducts 57 in excellent diastereoselectivity in a Darzens-type reaction via intermediate 56. This aziridination methodology was then used in the synthesis of MMP-inhibitors [63], as discussed later in this review. Aziridines are also obtained as primary products in the addition of chloromethyl phosphonamide $\mathbf{2 8 d}$ to imines. The initial attack leads to a $\alpha$-chloro- $\beta$-amino phosphonamide adduct as intermediate, which then undergoes intramolecular cyclization to form the aziridine ring after elimination of chloride. When $N$-substituted aromatic imines are used, the corresponding aziridines can be reduced at the benzylic carbon to give $\alpha$-aminophosphonic acids [64].

\section{Synthesis of phosphonamides}

There are four major methods for the synthesis of phosphonamides: (A) Arbuzov reaction, (B) condensation of diamines with phosphonic acid dichlorides, (C) nucleophilic displace- ment, and (D) alkylation of 2-oxo-1,3,2-diazaphospholidine (Scheme 9). All of these methods were employed to prepare the phosphonamide reagents used in the synthesis of the natural products and bioactive compounds discussed in this review.

\section{Phosphonamides by Arbuzov reaction}

An example for the application of the Arbuzov reaction is the synthesis of phosphonamide $(R, R)$-28a. Thus, heating of $(R, R)$ $N, N$ '-dimethyl-1,2-diaminocyclohexane (58) with hexamethylphosphorus triamide gave the distillable phospholane 59, which was further converted with ethanol into $\mathbf{6 0}$. Treatment with ethyl iodide in an Arbuzov reaction provided the desired ethyl phosphonamide 28a (Scheme 9A) [1,30]. Cyclic phosphonamides derived from $C_{2}$-symmetric diamines such as $\mathbf{2 8 a}$ do not have a stereogenic P-atom and therefore exist as a single pair of enantiomers. An example for the synthesis of a complex phosphonamide by the Arbuzov reaction can be found in the total synthesis of estrone (12) [44], as discussed later in this review.

\section{Phosphonamides by condensation of diamines with phosphonic acid dichlorides}

The most commonly applied method for the synthesis of simple phosphonamides is the condensation of phosphonic acid dichlorides with a diamine. Thus, treatment of acid dichloride $\mathbf{6 2}$ with

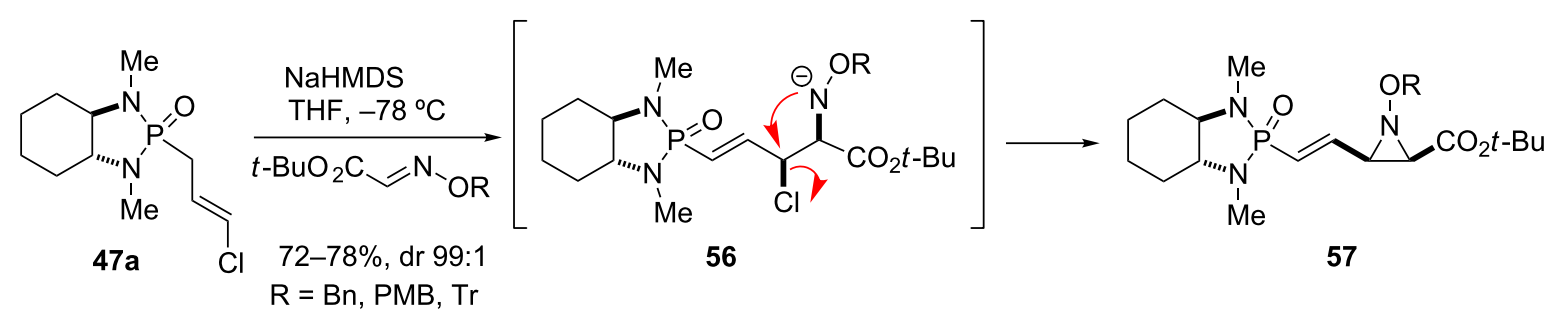


A<smiles>CNC1CCCC[C@H]1N</smiles>

58<smiles>CN1C2CCCCC2N(C)P1C</smiles>

$80 \%$

$\mathrm{EtOH}$,

$\mathrm{PhH}, \Delta$
$\underset{\mathrm{PhH}, \Delta}{\stackrel{\mathrm{EtI}}{\longrightarrow}}$

(2 steps)

28a

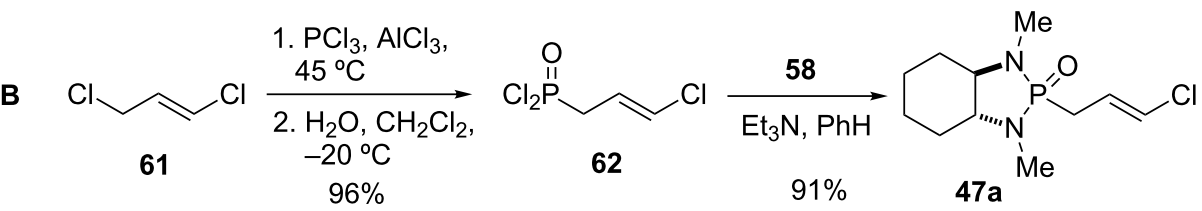<smiles>C=CCP(=O)(Cl)Cl</smiles>

63

\section{1. (-)-ephedrine,}

\section{$\overrightarrow{2 .}$ chromatographic separation}

$90 \%$, dr $1: 1$<smiles>C=CCP1(=O)OC(c2ccccc2)C(C)N1C</smiles>

cis-64a<smiles>C=CCP1(=O)OC(c2ccccc2)C(C)N1C</smiles>

trans-64b

C

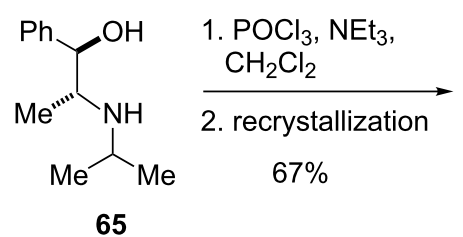<smiles>C=CCC(=O)OC(C)N1[C@H](C)[C@@H](c2ccccc2)OP1(=O)Cl</smiles>

66<smiles>C=CCP1(=O)OC(c2ccccc2)[C@@H](C)N1C(C)C</smiles>

trans-67<smiles>CNC1CCCC[C@H]1NC</smiles>

58

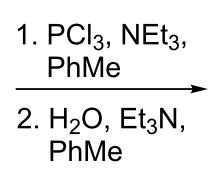
$52 \%$<smiles>CN1C2CCCCC2N(C)P1(=O)O</smiles>

68

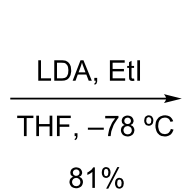

$81 \%$<smiles>CCP1(=O)N(C)C2CCCCC2N1C</smiles>

28a

Scheme 9: Synthesis of phosphonamides by (A) Arbuzov reaction, (B) condensation of diamines with phosphonic acid dichlorides, (C) nucleophilic displacement, (D) alkylation of phosphorus acid diamides $[1,5,6,28,30,51,69]$.

$(R, R)$ - $N, N$ '-dimethyl-1,2-diaminocyclohexane (58) afforded cyclopropanation reagent 47 a $[28,51]$. The required phosphonic acid dichlorides can be obtained either from chlorination of phosphonic acids $[65,66]$ or from treatment of an allyl chloride such as $\mathbf{6 1}$ with phosphorus trichloride followed by hydrolysis to give $\mathbf{6 2}[15,67]$. Reactions of unsymmetrical amines or aminoalcohols such as ephedrine with phosphonic acid dichlorides result in the generation of a stereogenic center at the P-atom and thus to diastereomeric phosphonamides cis-64a and trans-64b, which typically can be separated by chromatography [5].

Cyclopropanation reagent 47a was used in the total synthesis of anthoplalone (8) [56] and ambruticin S (14) [28], whereas an unsymmetrical phosphonamide of type $\mathbf{6 4}$ was used in the synthesis of PTP inhibitors [68], and methyl jasmonate [48], as discussed later in this review.

\section{Nucleophilic displacement}

The stereoselective synthesis of unsymmetrical phosphonamides 67 by nucleophilic displacement was reported by Hua and co-workers [6]. Treatment of aminoalcohol 65 with phosphoryl chloride provided 66 as a mixture of diastereomers ( $\mathrm{dr}$ 93:7), from which pure 66 was obtained by recrystallization. Chloride displacement at phosphorus with allylmagnesium bromide proceeded with retention of configuration to give allyl phosphonamide 67. A similar displacement reaction was used to generate a phosphonamide reagent in the synthesis of squalene synthase inhibitors [36] and is discussed later in this review.

\section{Phosphonamides by alkylation of phosphorus acid diamides}

Spilling and co-workers reported the preparation of alkyl phosphonamides through alkylation of bicyclic phosphite anions [69-71]. Thus, condensation of diamine $\mathbf{5 8}$ with phosphorus 
trichloride followed by hydrolysis of the formed 2-chloro-1,3,2diazaphospholidine with one equivalent of water gave phosphorus acid diamide $\mathbf{6 8}$. The latter could be deprotonated with LDA at low temperature and alkylated to give phosphonamide 28a. Spilling's alkylation methodology was used in the total synthesis of jerangolid A (22) [27] and ambruticin S (14) [28].

\section{Application in total synthesis Polyoximic acid (1993)}

Polyoximic acid (9) is a unique amino acid that occurs only as a component of polyoxins A, F, H, and $\mathrm{K}$, which exhibit antibiotic properties [72]. Originally, the stereochemistry of the exocyclic double bond of polyoximic acid was incorrectly assigned as $E$ based on a low resolution nOe experiment (Figure 3). The total synthesis of polyoximic acid (9) by Hanessian and co-workers led to a reassignment of its structure and that of the parent molecules, such as polyoxin A (69) [2426].<smiles>C[C@@]1(C(NC(=O)C(N)C(O)C(O)COC(N)=O)C(=O)I)OC(n2cc(CO)c(=O)[nH]c2=O)[C@H](O)[C@@H]1O</smiles>

polyoxin A (69)<smiles>C/C=C1\CN(CC)C1C(=O)O</smiles>

original structure<smiles>C/C=C1/CN(CC)C1C(=O)O</smiles>

revised structure polyoximic acid (9)
Figure 3: Original and revised structure of polyoxin A (69) [24-26].

The synthesis of the $E$-isomer of polyoximic acid started from protected D-serine 70, which was converted into diazoketone $\mathbf{7 1}$ by reacting a mixed anhydride with diazomethane (Scheme 10). Azetidinone $\mathbf{7 2}$ was then formed through a rhodium-catalyzed intramolecular carbenoid insertion into the $\mathrm{N}-\mathrm{H}$ bond as the first pivotal step of the synthesis. The next key step was to introduce the exocyclic double bond with control of the stereochemistry of the double bond. For that purpose, a variety of 'typical' Wittig and Horner-Wadsworth-Emmons reagents were screened. In addition, cyclic phosphonamides were utilized as olefination reagents (Table 1).

Employing phosphonamides $24 \mathrm{e}$ and $\mathbf{7 7}$ in the olefination of $\mathbf{7 2}$ favored the formation of the desired $E$-isomer of 73a, however the mixture of isomers was inseparable by normal chromatographic methods. The chiral backbone of $\mathbf{7 7}$ had a beneficial

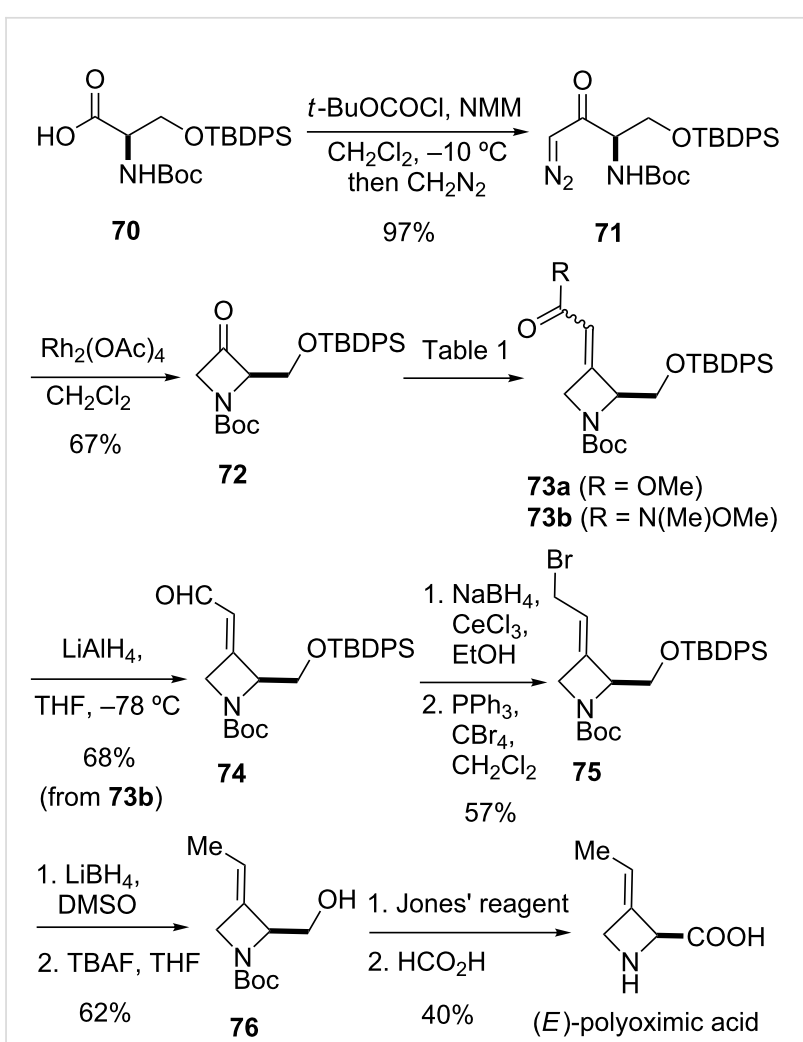

(9)

Scheme 10: Synthesis of (E)-polyoximic acid (9) [24-26].

effect on the stereoselectivity of the olefination, with an improved $E / Z$ ratio of 91:9 compared to the achiral analogue 24e (Table 1, entries 1 and 2). Employing phosphonate-Weinreb amide 78 and phosphonamide-Weinreb amide 79 not only afforded good $E / Z$ ratios of $87: 13$ to $88: 12$ of $73 \mathbf{b}$ but also provided a product that could now be separated by column chromatography (Table 1, entries 3 and 4). Reduction of amide $E-73 b$ by $\mathrm{LiAlH}_{4}$ to aldehyde $\mathbf{7 4}$ and further reduction under Luche conditions delivered an allylic alcohol, which was then converted into bromide 75. Debromination and cleavage of the TBDPS protecting group gave protected amino-alcohol $\mathbf{7 6}$. Finally, Jones oxidation and removal of the $N$-Boc protecting group produced crystalline $(E)$-polyoximic acid $(E-9)$, whose structure was unambiguously confirmed by X-ray analysis. A comparison of the NMR spectrum of $E-9$ with an authentic sample of natural polyoximic acid led to the conclusion that the natural product contains a $Z$-double bond, contrary to the original assignment (Figure 3).

The synthesis of $Z$-polyoximic acid (Z-9) was eventually achieved through a similar sequence as shown in Scheme 10. Replacing phosphonamide 79 with Wittig-reagent 80 as olefinating reagent gave a separable $E / Z$ mixture in a ratio of $1: 9$ in favor of the desired $Z$-isomer of $\mathbf{7 3 b}$ (Table 1, entry 5 ). The 
Table 1: Horner-Wadsworth-Emmons olefination of ketone 72 [26].

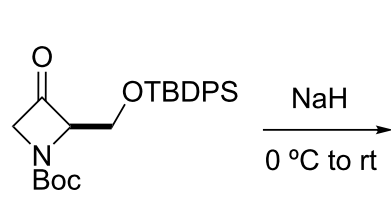

72<smiles>[R]C(=O)C=C1C[R16](=O)O1</smiles>

73a $(\mathrm{R}=\mathrm{OMe})$

73b $(\mathrm{R}=\mathrm{N}(\mathrm{Me}) \mathrm{OMe})$

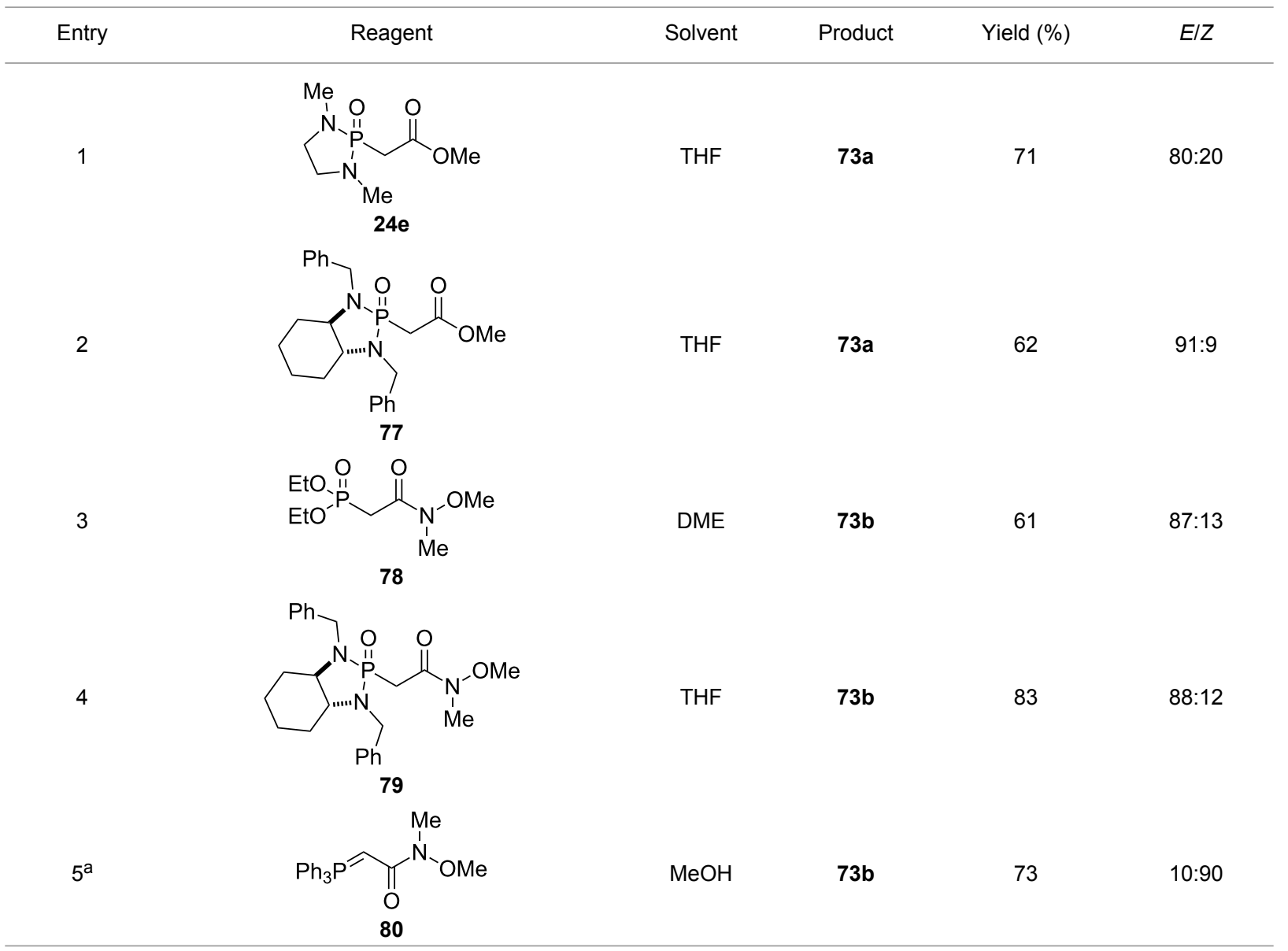

awithout $\mathrm{NaH}$, at $-78^{\circ} \mathrm{C}$.

latter was then transformed into Z-9 in an analogous fashion as described for the $E$-isomer. Comparison of the spectroscopic and physical data of synthetic Z-9 with the amino acid derived from the natural product confirmed the revised structure of the latter [24-26,73].

\section{Acetoxycrenulide (1995)}

The marine toxin acetoxycrenulide (10) was isolated independently from small brown seaweed of the family Dictyotaceae and from the sea hare $[74,75]$. Paquette and co-workers reported the first and only total synthesis of this diterpene (Figure 4) $[41,42]$. The cyclooctanoid core of the target was envisioned to be formed by a Claisen rearrangement of intermediate 81. The latter and most of its stereocenters would originate from lactone 82, which in turn is the product of a conjugate addition of chiral allyl phosphonamide reagent $\mathbf{2 8 c}$ to butenolide $\mathbf{8 3}$ prepared from $(R)$-citronellol. The correct installation of the stereocenters of $\mathbf{8 2}$ was crucial to the success of the synthesis, as they would form a template for the stereocontrolled incorporation of the remaining stereocenters.

The construction of butenolide $\mathbf{8 3}$ started from $(R)$-citronellol (84), which could in principle, deliver the entire alkenyl side chain of acetoxycrenulide (10) (Scheme 11). However, the 


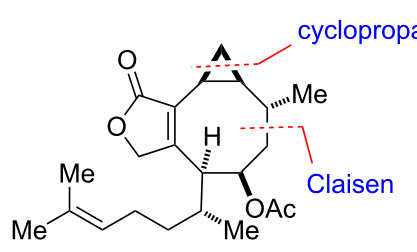

(+)-acetoxycrenulide (10)

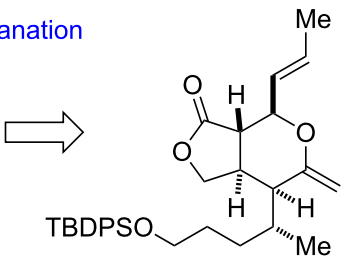

81

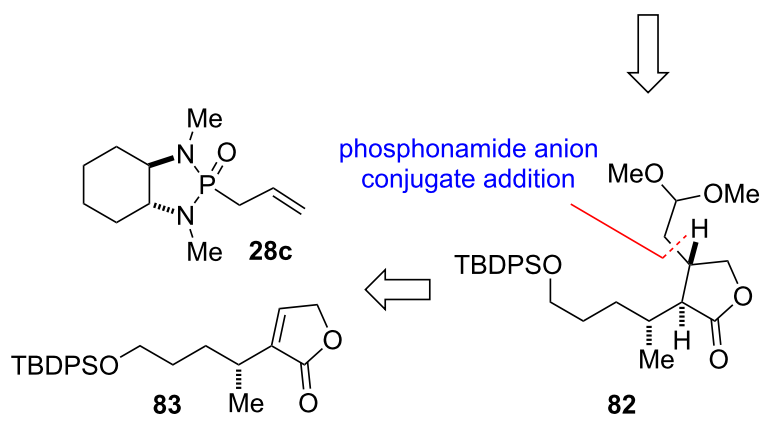

Figure 4: Key assembly strategy of acetoxycrenulide (10) $[41,42]$.

double bond needed to be transformed into a TBDPS ether as it would not survive the late-stage cyclopropanation (Figure 4). Thus, protection of the primary alcohol as acetate, ozonolysis with reductive work-up, treatment with TBDPSCl and ensuing hydrolytic removal of the acetate yielded mono-protected diol 85. Conversion into methyl ester $\mathbf{8 6}$ by a three-step procedure and subsequent alkylation with allyl bromide gave alkene $\mathbf{8 7}$. Ozonolysis with reductive work-up was followed by spontaneous cyclization to the corresponding $\gamma$-lactone, which was then transformed into $\mathbf{8 3}$ by means of $\alpha$-selenenylation, oxidation, and elimination (Scheme 11).

With butenolide 83 in hand the stage was set for one of the key steps of the synthesis. Addition of the anion of phosphonamide $\mathbf{2 8 c}$ to $\mathbf{8 3}$ proceeded with a high level of facial and cis/transselectivity to afford adduct $\mathbf{8 8}$ as a single diastereomer with the correct stereochemistry. Removal of the chiral auxiliary by ozonolysis, protection of the resulting aldehyde, reduction of the lactone ring to the lactol, and treatment with methylenetriphenylphosphorane delivered 89. Mild acidic hydrolysis of the acetal followed by oxidation then yielded 90 with the $\gamma$-lactone unit that constitutes ring A of acetoxycrenulide. Cleavage of the double bond by ozonolysis and addition of (phenylseleno)methyllithium followed by protection of the formed hydroxy group provided $\mathbf{9 1}$ as a single diastereomer. Condensation of $\mathbf{9 1}$ with $(E)$-crotonaldehyde and heating of the obtained aldol adduct with catalytic amount of acid formed tetrahydropyran $\mathbf{9 2}$ as key intermediate of the synthesis. Oxidation of 92 and heating to $220{ }^{\circ} \mathrm{C}$ resulted in a concurrent selenoxide elimina- tion and Claisen rearrangement to give 93 via intermediate 81 . Face-selective Simmons-Smith cyclopropanation, reduction of both carbonyl groups, and chemoselective oxidation of the formed lactol with Fetizon's reagent afforded 94. The final steps of the synthesis involved conversion to the corresponding $\alpha, \beta$-unsaturated lactone $\mathbf{9 5}$ and modification of the side chain to re-build the original double bond to eventually give $(+)$ acetoxycrenulide (10) [41,42].

\section{Squalene synthase inhibitor (1996)}

Inhibitors of squalene synthase have sparked interest as selective cholesterol lowering agents [76,77]. The enzyme is involved in the first committed step in the cholesterol synthesis and catalyses the conversion of two molecules of farnesyl diphosphate into squalene, which is later converted exclusively into various sterols, such as cholesterol, by a multi-step pathway [78]. The $\alpha$-phosphono sulfonate 19 was found to be a potent inhibitor of squalene synthase, however, only the racemic version was originally tested. Biller and co-workers designed an enantioselective synthesis of $\mathbf{1 9}$ based on an asymmetric sulfuration (route A) or asymmetric alkylation (route B) of a chiral phosphorus carbanion (Scheme 12) [36]. Deprotonation of $(R, R)$-28a and alkylation with 3-(3'-phenoxyphenyl)propyl iodide (96) gave 97. Sulfuration of the Li anion of 97 with tetramethylthiuram disulfide provided the adduct as a 3:1 mixture of diastereomers, with $\mathbf{9 8}$ as the major isomer. The low diastereoselectivivity observed for the sulfuration as compared to that reported for the alkylation of phosphonamides similar to 97 was explained with a longer $\mathrm{C}-\mathrm{S}$ bond in the transition state and the steric hindrance sensed by a thiuram relative to an alkyl halide. Further support for this theory comes from a control experiment, in which 97 was alkylated under the same conditions with benzyl bromide, leading to a 10:1 mixture of diastereomers. The pure diastereomer $\mathbf{9 8}$ was then hydrolyzed with mild acid to remove the chiral auxiliary and oxidized to diacid 99. Converison into its potassium salt yielded squalene synthase inhibitor $(S)$-19. In a similar sequence, the minor diastereomer from the sulfuration, 1-epi 98, was converted into the opposite enantiomer $(R)-\mathbf{1 9}$ (Scheme 12A).

Reversing the steps for the introduction of the alkyl chain and the sulfonate moiety with the aim to achieve better selectivity led to route B (Scheme 12B). Thus, treatment of 100, obtained from $(R, R)$ - $N, N$ '-dimethyl-1,2-diaminocyclohexane and phosphoryl chloride, with the anion generated from ethyl methanesulfonate followed by cleavage of the ethyl sulfonate gave tetrabutylammonium salt 101. Deprotonation of 101 followed by reaction of the dianion with 3-(3'-phenoxyphenyl)propyl iodide (96) provided adduct 102 with excellent selectivity ( $\mathrm{dr}>20: 1)$. Removal of the chiral auxiliary and purification by cation exchange finally afforded $(S)-\mathbf{1 9}$. 

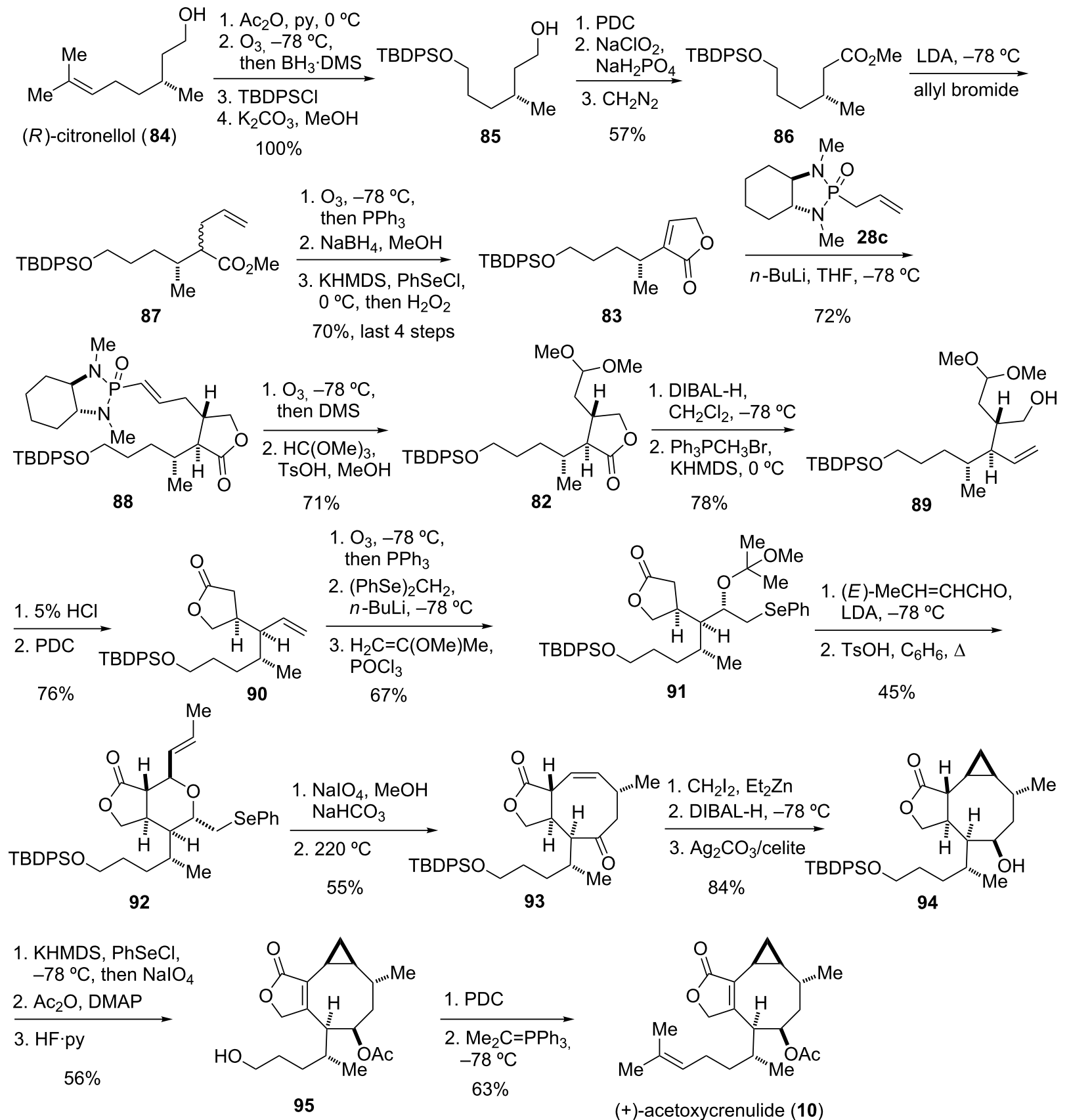

Scheme 11: Total synthesis of (+)-acetoxycrenulide (10) $[41,42]$.

Both enantiomers of 19 were tested in in vitro assays for their ability to inhibit squalene synthase. Enantiomer $(S)-\mathbf{1 9}$ was found to be 16 -fold more potent than the $(R)$-enantiomer, with $\mathrm{IC}_{50}$ values of 68 and $1120 \mathrm{nM}$, respectively [36].

\section{Fumonisin $B_{2}$ (1997)}

Fumonisin $\mathrm{B}_{2}$ (20) belongs to the family of fumonisin mycotoxins produced by fungi of the genus Fusarium, a common grain mold. It is a close structural analogue of fumonisin $\mathrm{B}_{1}$, the most prevalent member of the family of fumonisins $[79,80]$. Fumonisin $\mathrm{B}_{1}, \mathrm{~B}_{2}$ and other fumonisins frequently contaminate maize and other crops [81-83]. Kishi and co-workers adopted a convergent approach to fumonisin $\mathrm{B}_{2}$, with the molecule being cleaved into three main fragments 103-105 [45,46]. The connection of $\mathbf{1 0 3}$ and $\mathbf{1 0 4}$ under formation of the fumonisin backbone would employ a Wittig reaction, followed by attach- 


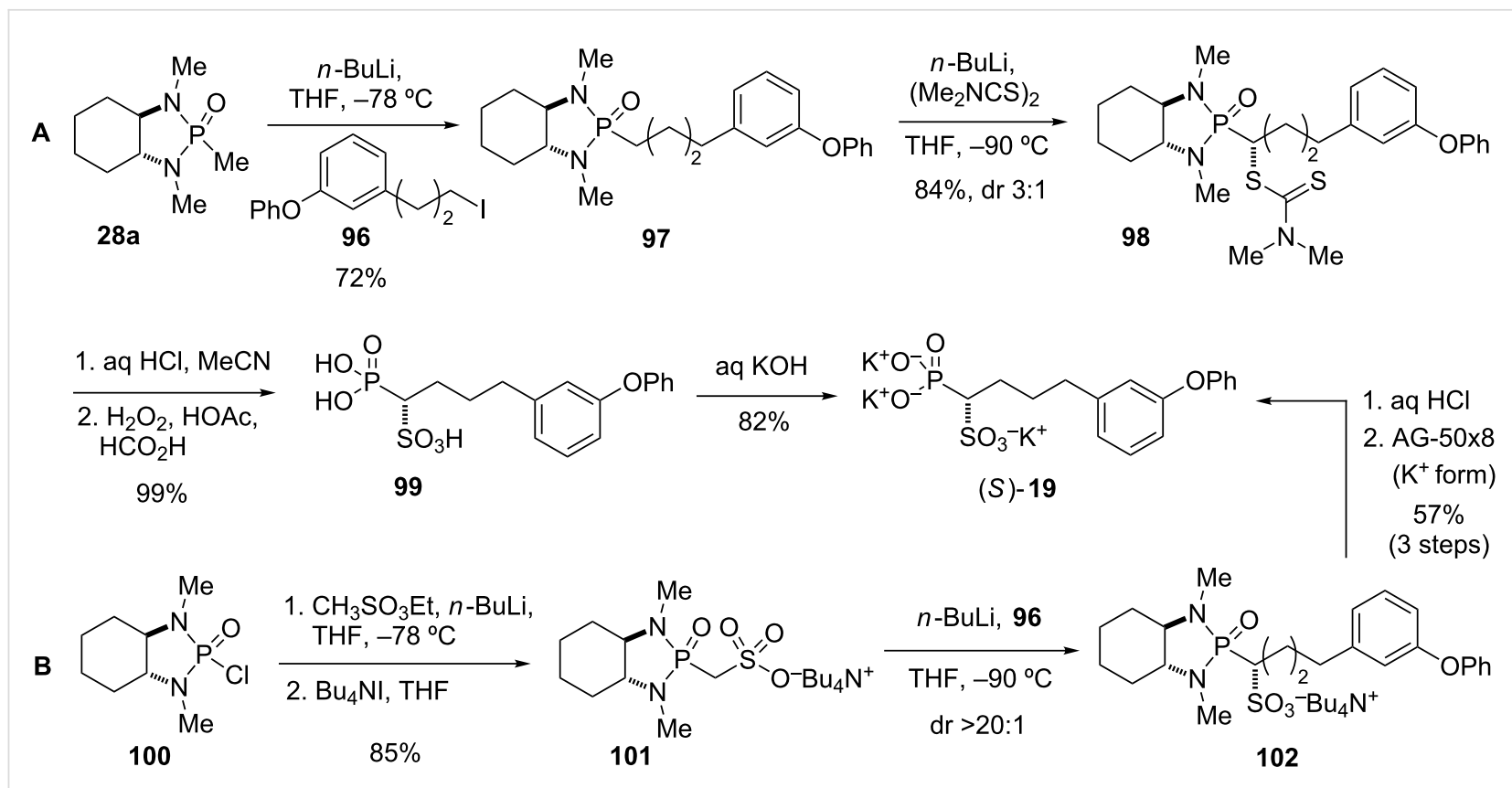

Scheme 12: Synthesis squalene synthase inhibitor 19 by asymmetric sulfuration (A) and asymmetric alkylation (B) of a phosphonamide anion [36].

ment of two molecules of tricarballylic acid (105). The latter fragment would be accessed by conjugate addition of the anion of phosphonamide 28c to tert-butyl sorbate (106) to give intermediate $\mathbf{1 0 7}$ followed by oxidative cleavage of the chiral auxiliary (Figure 5 and Scheme 13).

The preparation of $\mathbf{1 0 7}$ was performed as previously reported with minor modifications (Scheme 13) [37]. Thus, addition of the Li anion of 28c to tert-butyl sorbate (106) afforded adduct 107 with excellent diastereoselectivity. Cleavage of both double bonds by ozonolysis followed by oxidative work-up with Jones' reagent provided a monoprotected tricarballylic acid intermediate. Conversion of the free carboxylic acid moieties into their benzyl esters followed by cleavage of the tert-butyl ester gave 108. This fragment was then coupled with diol 109 to afford the fully protected fumonisin $B_{2}$ precursor 110 . Final hydrogenation and hydrogenolysis of all eight benzyl protecting groups was accomplished using Pearlman's catalyst under mild acidic conditions to give fumonisin $\mathrm{B}_{2}$ (20) $[45-47,84]$.

\section{Tricylic $\beta$-lactams (1997)}

$\beta$-Lactam antibiotics are the most prescribed and successful class of antibiotics developed and used in clinical practice. This broad class of antibiotics shares a highly reactive fourmembered $\beta$-lactam ring and includes penicillin derivatives, cephalosporins, monobactams, carbapenems, and other related compounds [85-87]. Approved drugs such as imipenem (111) and meropenem (112) (Figure 6) belong to the subclass of carbapenems, which are powerful antibiotics with a broad spec-

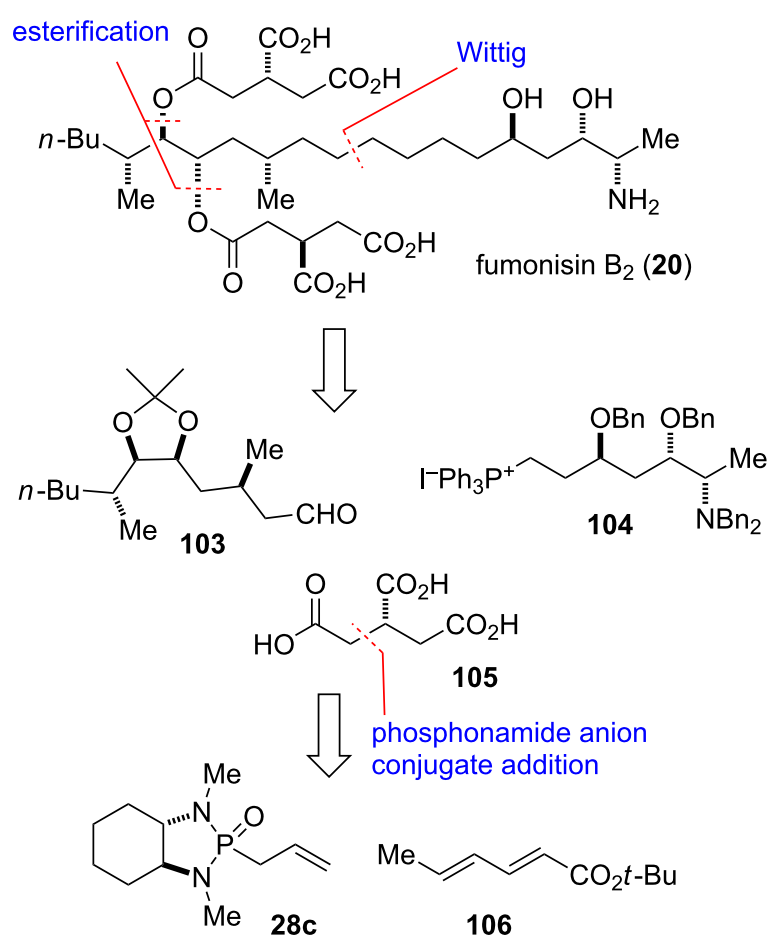

Figure 5: Key assembly strategy of fumonisin $B_{2}(20)$ and its tricarballylic acid fragment $105[45,46]$.

trum of activity against Gram-positive and Gram-negative bacteria and are often used as antibiotics for many hard-to-treat bacterial infections, such as Escherichia coli and Klebsiella pneumoniae $[88,89]$. Resistance of bacterial strains to antibi- 


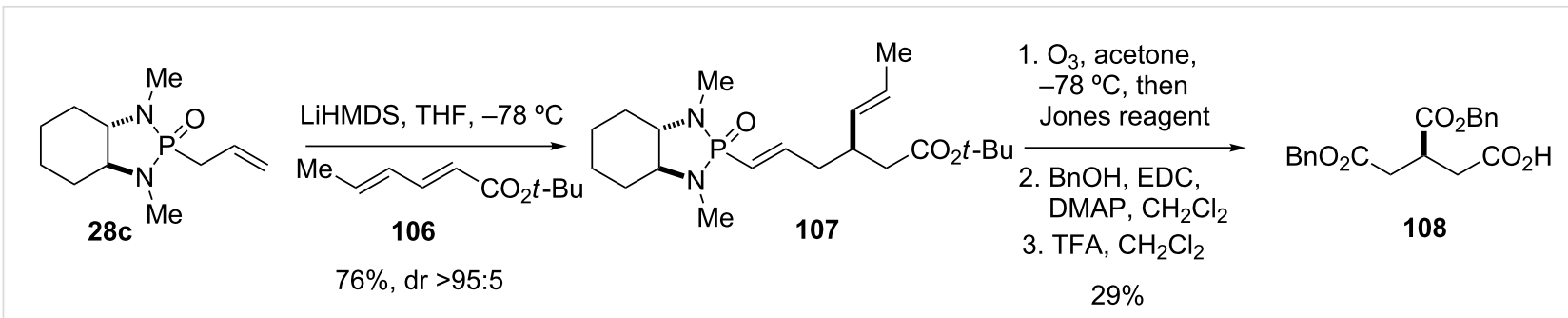

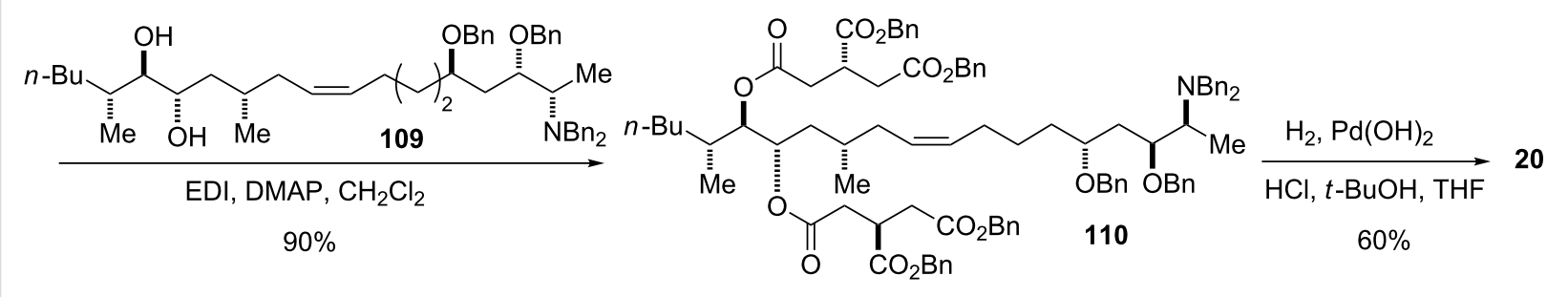

Scheme 13: Final steps of the total synthesis of fumonisin $B_{2}(20)[45,46]$.

otics has dictated the need for continuous development of existing and discovery of new antibiotics ever since the introduction of the first antibacterial agents in the first half of the $20^{\text {th }}$ century. In recent years, this trend has become a serious threat for public health with the emergence of carbapenemresistant enterobacteriaceae such as Klebsiella pneumoniae $[90,91]$.

In the 1990's, scientists at GlaxoWellcome developed sanfetrinem (113), a member of a novel class of tricyclic $\beta$-lactam antibiotics known as trinems [92,93]. Eventually the development of sanfetrinem was stopped in 2009 after phase II clinical trials [86], but the compound inspired others to study its structural variants. Hanessian and co-workers reported on the synthesis of analogs of sanfetrinem (113) [94-96], including the $5 \alpha$-hydroxyethyltrinems 23a,b (Figure 6) [97], as well as a total synthesis of sanfetrinem (113) [96].

The installation of the two-carbon side chain of $\mathbf{2 3}$ was achieved through a stereoselective conjugate addition of a phosphonamide allyl anion to an advanced intermediate (Scheme 14). The latter was constructed in four steps starting from cyclohexenone (41b). Thus, addition of the Li salt of $\mathbf{4 1 b}$ to allyl diethylphosphonoformate (114) afforded $\beta$-ketoester 115, which in turn was condensed with commercially available azetidinone $\mathbf{1 1 6}$ to give $\mathbf{1 1 7}$ as a mixture of diastereomers. Protection of the nitrogen with TBS triflate followed by deprotection of the allyl carboxylate with formic acid under palladium catalysis and subsequent decarboxylation yielded enone $\mathbf{1 1 8}$ as a single diastereomer.

Addition of the Li anion of phosphonamide 24c to enone 118 afforded adduct $\mathbf{1 1 9}$ as a single isomer, with the attack occur-

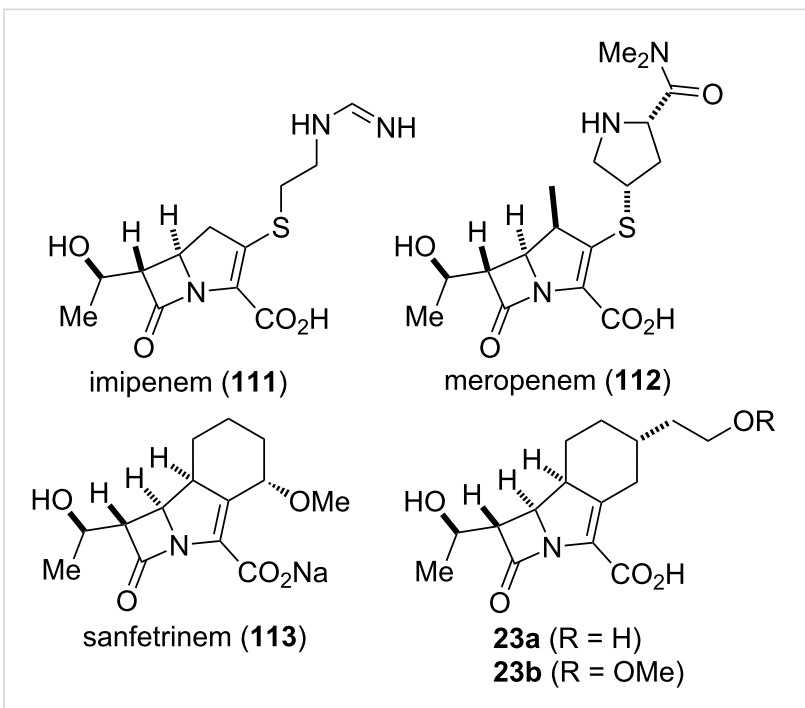

Figure 6: Selected examples of two subclasses of $\beta$-lactam antibiotics - carbapenems (111 and 112) and trinems (113 and 23).

ring to the less hindered face of the enone. Further elaboration of the side chain was achieved by ozonolysis to give an aldehyde, selective reduction of the latter with 9-BBN, and protection of the obtained primary alcohol as its TBS ether. $N$-Deprotection to give $\mathbf{1 2 0}$ was followed by acylation with benzyloxalyl chloride and treatment with triethylphosphite at elevated temperature to yield tricyclic intermediate 121. Cleavage of the TBS ethers and hydrogenolysis of the benzyl ester in presence of amidine $\mathbf{1 2 2}$ yielded trinem 23a as its amidinium salt $\mathbf{1 2 3}$.

Trinem 123 exhibited antibacterial activity against a variety of strains, with MIC's of $1.0 \mu \mathrm{g} / \mathrm{mL}$ against Staphylococcus aureus $853 \mathrm{E}$ and $0.1 \mu \mathrm{g} / \mathrm{mL}$ against Streptococcus pneumoniae 3512. The antibacterial activity of $\mathbf{1 2 3}$ was considerably weaker 


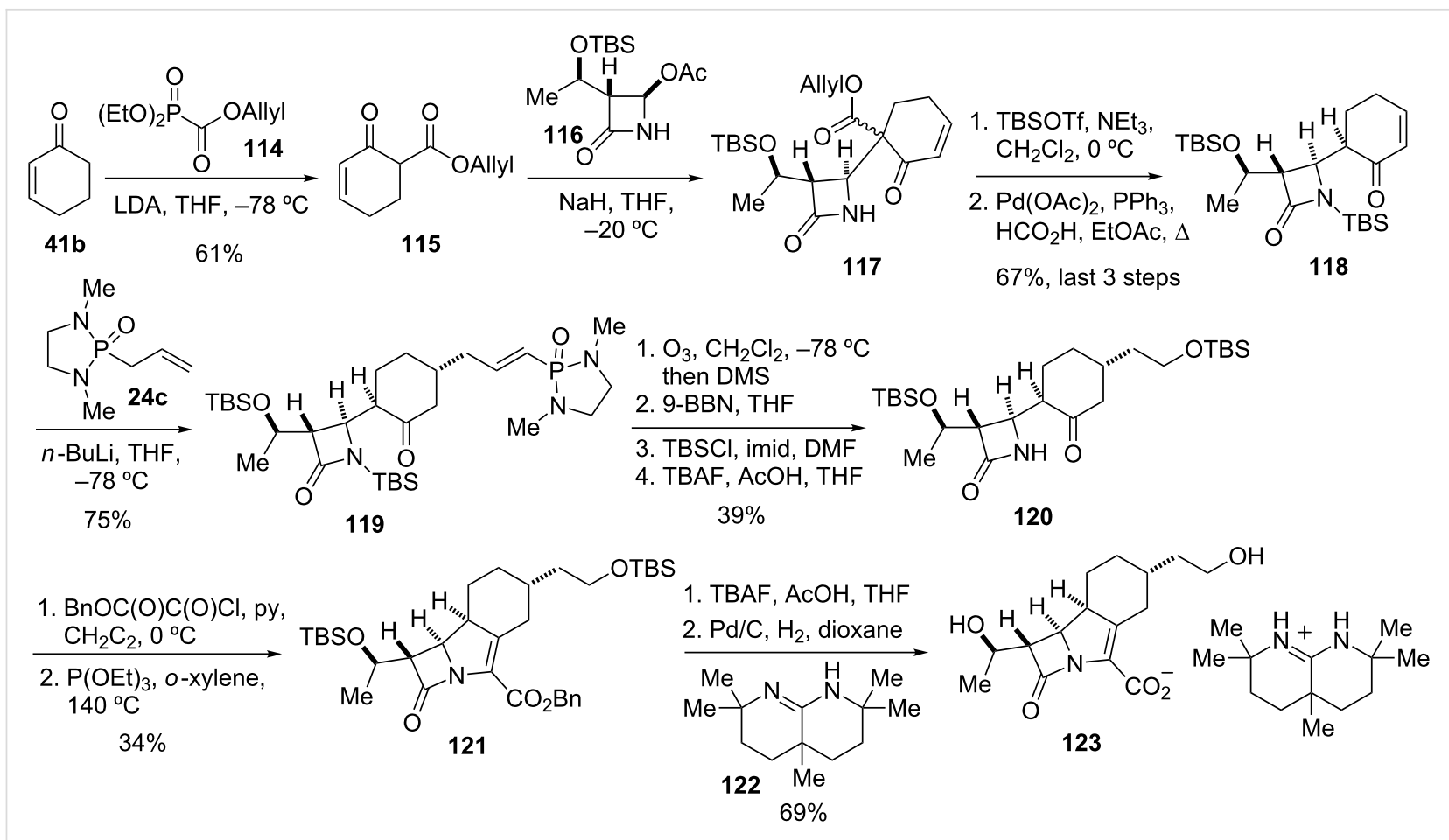

Scheme 14: Synthesis of tricyclic $\beta$-lactam antibiotic 123 [97].

compared to imipenem (111) and sanfetrinem (113), which showed MIC's of 0.06 and $0.2 \mu \mathrm{g} / \mathrm{mL}$, respectively, against $S$. aureus and $0.01 \mu \mathrm{g} / \mathrm{mL}$ against $S$. pneumoniae. The lack of potency of 123 was attributed in part to the missing $\alpha$-orientated 4-alkoxy substituent present in sanfetrinem (113), which may act as a potential leaving group and appears to be crucial for activity [97].

\section{Anthoplalone (1999)}

Isolated from the Okinawan actinian Anthopleura pacifica, anthoplalone (8) is a secosesquiterpene with a tetrasubstituted trans-cyclopropane subunit. The compound shows modest cytotoxic activity against murine melanoma cells $[98,99]$. The first enantioselective total synthesis of anthoplalone was achieved by Hanessian and co-workers and utilized their chloroallyl phosphonamide anion cyclopropanation methodology [56]. Thus, deprotonation of $\mathbf{4 7} \mathbf{a}$ with butyllithium at low temperature and addition to tert-butyl 3,3-dimethylacrylate (124) provided adduct $\mathbf{1 2 5}$ as a single diastereomer (Scheme 15). Removal of the chiral auxiliary by ozonolysis and subsequent reduction afforded alcohol 126. Chain extension was accomplished through a one-pot Swern oxidation/Wittig olefination protocol followed by hydrogenation to give ketone 127. For further extension of the carbon chain and installation of the trisubstituted double bond, a modified Julia olefination with imidazole sulfone 128 was employed [100-102]. Thus, reaction of ketone $\mathbf{1 2 7}$ with the lithium anion of sulfone $\mathbf{1 2 8}$ and treatment of the obtained $\beta$-hydroxysulfone with $\mathrm{SmI}_{2}$ led to olefin 129 as a 2:1 mixture of $E / Z$-isomers. After reduction of the tert-butyl ester to the primary alcohol, the $E / Z$-isomers could be separated chromatographically. Cleavage of the ketal under acidic conditions to reveal the ketone moiety and final oxidation of the primary alcohol with tetrapropylammonium perruthenate (TPAP) completed the first enantioselective total synthesis of anthoplalone (8) and confirmed the absolute configuration of the natural product $[56,103,104]$.

\section{PTP inhibitors (2000)}

Protein tyrosine phosphatases (PTPs) are part of a superfamily of enzymes that catalyze protein tyrosine dephosphorylation. They are key regulators in various, crucial kinase-dependent signal transduction pathways and act to counterbalance the kinases. In particular, PTP1B has attracted considerable attention for its role in the complex insulin-signaling pathway. It has been shown that overexpression of PTP1B contributes to diabetes and obesity $[105,106]$. Therefore, inhibititors of PTP1B may have potential as treatment for type-2 diabetes [107-110].

Hydrolytically-stable phosphotyrosyl mimetics have been developed as PTP1B inhibitors, including molecules such as 131 containing an $\alpha, \alpha$-difluoromethylenephosphonic (DFMP) moiety (Figure 7). In particular, peptides bearing a phosphonodifluoromethylphenylalanine $\left(\mathrm{F}_{2} \mathrm{Pmp}\right)$ group such as $\mathbf{1 3 0}$ have 


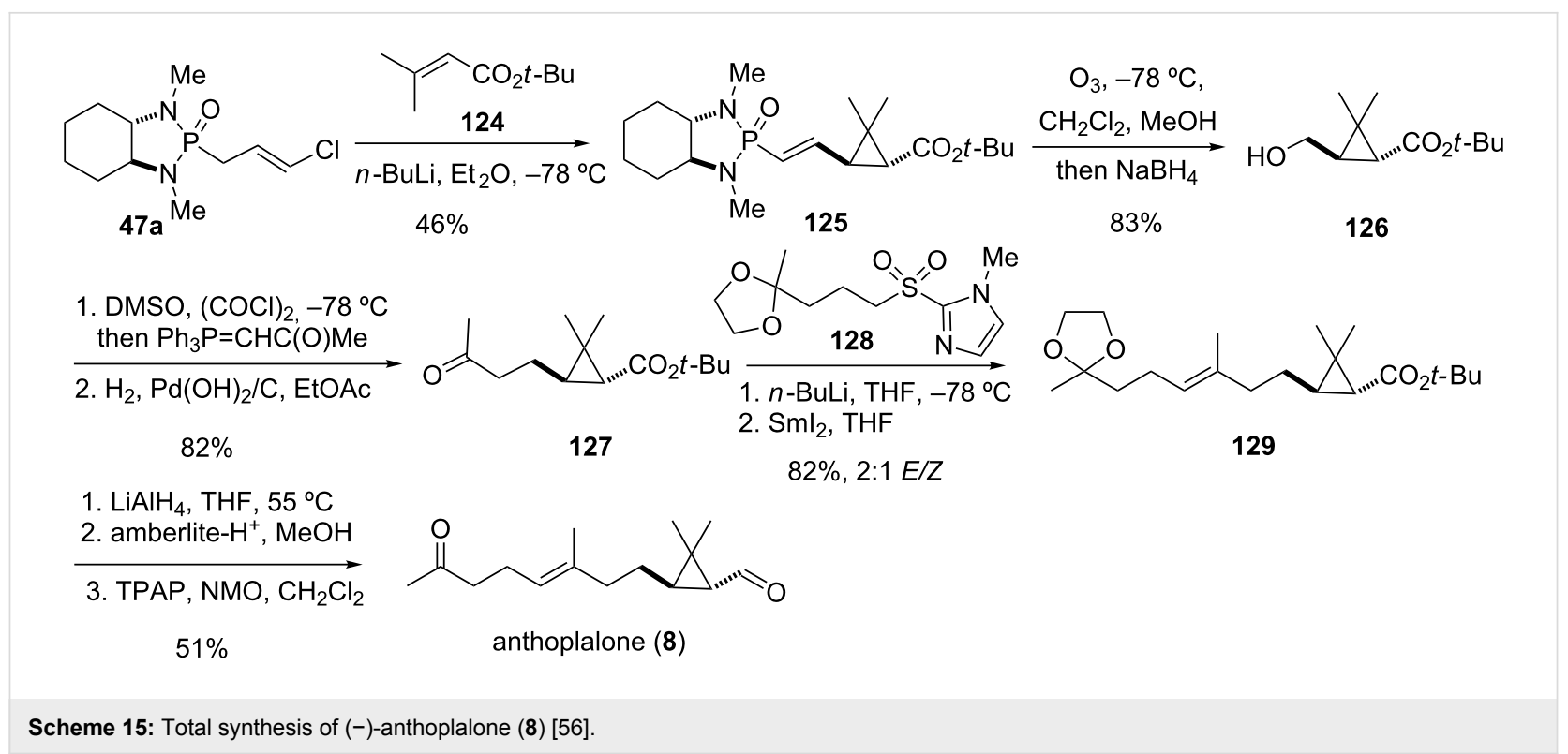<smiles>NC(=O)C(Cc1ccc(CC(F)(F)P(=O)(O)O)cc1)NC(=O)C(CC(=O)O)NC(=O)Cc1ccc(C(F)(F)P(=O)(O)O)cc1</smiles><smiles>[R]C([R20])([R6])c1ccc2ccccc2c1</smiles>

$\mathrm{R}^{1}=\mathrm{F}, \mathrm{R}^{2}=\mathrm{H}: S-\mathbf{1 6} \mathbf{a}$

$\mathrm{R}^{1}=\mathrm{H}, \mathrm{R}^{2}=\mathrm{F}: R-16 \mathrm{a}$

$\mathrm{R}^{1}, \mathrm{R}^{2}=\mathrm{F}$

132

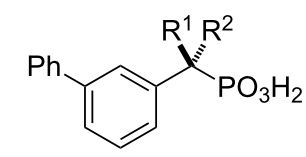

$R^{1}=F, R^{2}=H: S-16 b$

$\mathrm{R}^{1}=\mathrm{H}, \mathrm{R}^{2}=\mathrm{F}: R-16 \mathrm{~b}$

$R^{1}, R^{2}=F$ :

133

Figure 7: Protein tyrosine phosphatase (PTP) inhibitors 130, 131 and model compounds 16,132 and 133 [68].

been shown to be among the most potent inhibitors with nanomolar potency against PTP1B [110,111].

Taylor and co-workers were interested to study $\alpha$-monofluoroalkylphosphonic acids as PTP1B inhibitors in comparison to their difluoro analogues and compounds $16 \mathbf{a}, \mathbf{b}$ and $\mathbf{1 3 2 , 1 3 3}$ were chosen as model PTP1B inhibitors [68]. The enantiopure $\alpha$-monofluoroalkylphosphonic acids were synthesized by diastereoselective fluorination of phosphonamides bearing (-)ephedrine as chiral auxiliary, originally introduced by Sting and
Steglich for the synthesis of aminoalkylphosphonic acids [7] (Scheme 16). Thus, condensation of the phosphonic acid dichloride obtained from $\mathbf{1 3 4 a , b}$ with ephedrine yielded a separable mixture of diastereomeric phosphonamides, trans-135a,b and cis-136a,b. The fluorination with $N$-fluorobenzenesulfonimide (NFSI) of either trans-135a or cis-136a was found to be strongly dependant on the base used to generate the phosphonamidate anion. The best diastereomeric ratio of 3.8:1 (58\% de) in favor of trans-S-137a was observed with NaHMDS as base in the reaction of trans-135a. The cis-isomer 136a gave a similar result with NaHMDS, whereas the fluorination of $m$-(phenyl)benzyl phosphonamides $\mathbf{1 3 5 b}$ and $\mathbf{1 3 6} \mathbf{b}$ proved to be less selective. Although the diastereoselectivity was modest at best, the fluorinated products trans-S-137a,b and trans- $R$ $\mathbf{1 3 8 a}, \mathbf{b}$ could be readily separated by chromatography. Higher selectivities of up to $70 \%$ de were achieved in the fluorination step when trans- $(R, R)-N, N$ '-dimethyl-1,2-diaminocyclohexane (58) was employed as chiral auxiliary, however, the diastereomeric products were not separable by chromatographic means.

Cleavage of the ephedrine auxiliary was accomplished by a three-step protocol. Treatment of $\mathbf{1 3 7} \mathbf{a}, \mathbf{b}$ and $\mathbf{1 3 8} \mathbf{a}, \mathbf{b}$ with trifluoroacetic acid in methanol followed by reaction with TMSBr and subsequent hydrolysis of the TMS ester gave the free acids $(S)-\mathbf{1 6} \mathbf{a}, \mathbf{b}$ and $(R)-\mathbf{1 6 a}, \mathbf{b}$, respectively as pure enantiomers.

Compounds 16a,b, 132 and 133 were found to be inhibitors of PTP1B. The monofluoro ( $R$ )-enantiomers $R-16$ a $\left(\mathrm{IC}_{50} 675 \mu \mathrm{M}\right)$ and $R-16 \mathrm{~b}(315 \mu \mathrm{M})$ were about 10 -fold more potent than the corresponding $(S)$-enantiomers $\left(\mathrm{IC}_{50} 7500 \mu \mathrm{M}\right.$ and $3500 \mu \mathrm{M}$

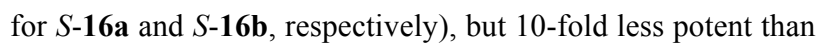
the difluoro analogues 132 and $\mathbf{1 3 3}\left(\mathrm{IC}_{50} 71 \mu \mathrm{M}\right.$ and $33 \mu \mathrm{M}$, 


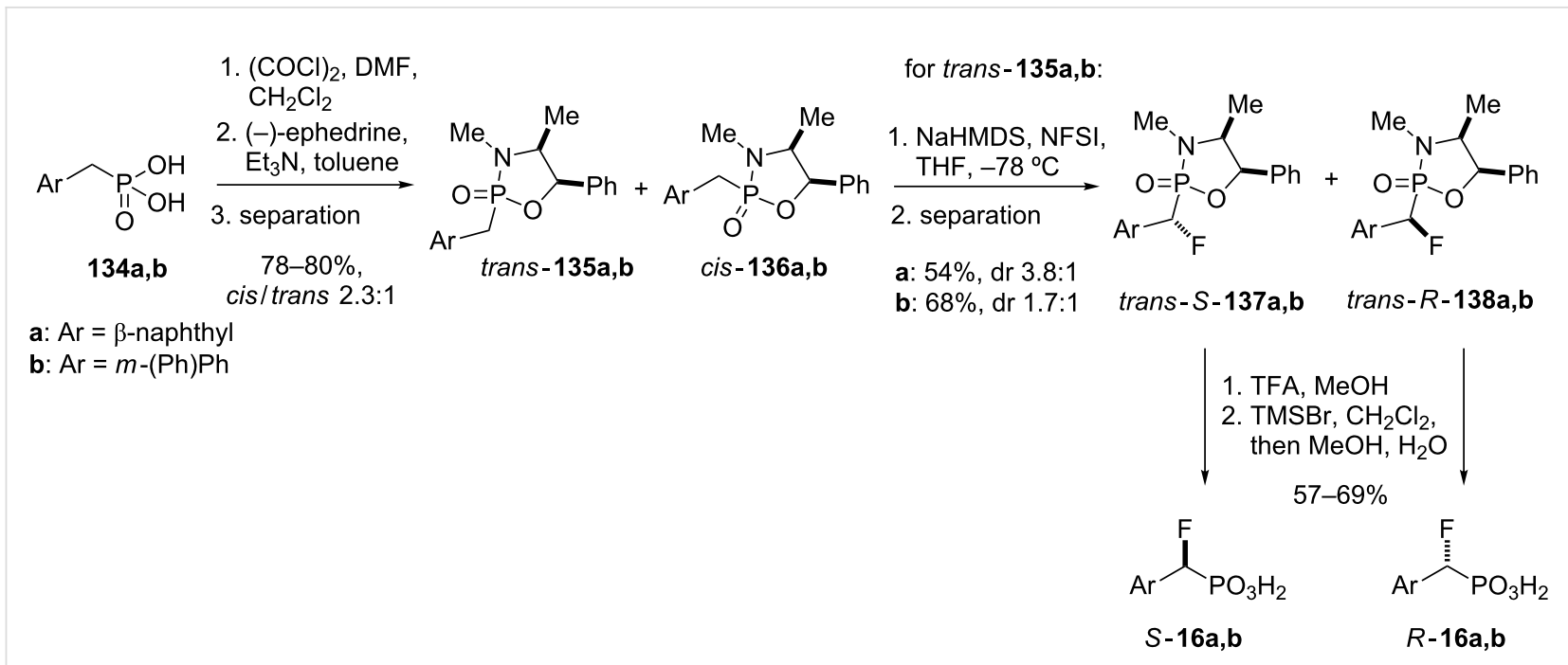

Scheme 16: Synthesis of model PTP inhibitors 16a,b [68]

respectively). The inhibition studies indicated that the pro- $S$ fluorine in difluoro inhibitors $\mathbf{1 3 2}$ and $\mathbf{1 3 3}$ is essential for good inhibition, although the pro- $R$ fluorine contributes significantly more towards PTP1B affinity [68].

\section{MMP inhibitors (2001)}

The matrix metalloproteinases (MMPs) are a family of structurally-related, zinc-containing enzymes that play a critical role in the degradation and remodelling of extracellular matrix. Over expression of MMPs has been associated with various physiological and pathological processes such as morphogenesis, angiogenesis, tissue repair, cirrhosis, arthritis, and metastasis, thus raising the possibility that inhibitors of these enzymes may possess therapeutic potential $[112,113]$.

As part of studies on conformationally constrained MMP inhibitors by Hanessian and co-workers, trans- and cis-aziridines scaffolds were used as peptidomimetics to construct a series of hydroxamic acids analogs such as 17 (Scheme 17) [63]. While the trans-aziridines were prepared by conjugate addition of $O$-benzylhydroxylamine to $\alpha, \beta$-unsaturated amides bearing a chiral oxazolidinone auxiliary, facile access to the cis-aziridine series was possible by using chiral chloroallyl phosphonamide 47a. Thus, the addition of the anion of 47 a to tert-butylglyoxylate $O$-benzylamine (139) led to aziridine $\mathbf{1 4 0}$ as a single diastereomer. Ozonolysis followed by reductive work-up provided alcohol 141. Coupling under Mitsunobu conditions with an appropriate alcohol, e.g., 3-hydroxypyridine, reduction of the tert-butyl ester with DIBAL-H, and treatment with TBS triflate gave silyl ether 142. Hydrogenolysis of 142 using $\mathrm{Pd} / \mathrm{BaSO}_{4}$ produced the free aziridine, which was then converted to the corresponding sulfonamide with para-methoxyphenyl (PMP)

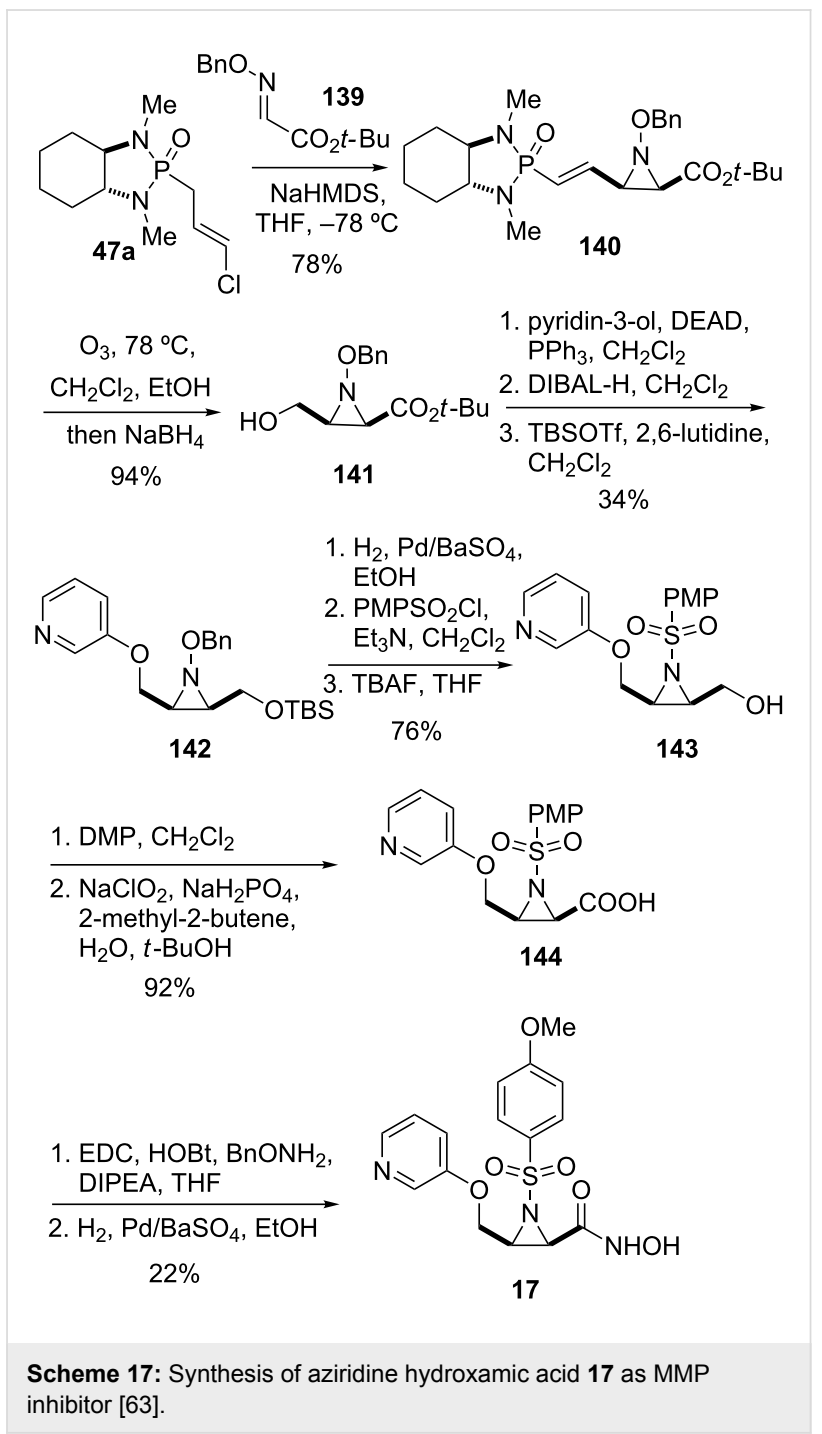


sulfonyl chloride. Cleavage of the silyl ether moiety with TBAF gave primary alcohol 143 , which was oxidized to the corresponding acid 144 by a two-step protocol consisting of treatment with Dess-Martin periodinane followed by Pinnick oxidation. Hydroxamic acid $\mathbf{1 7}$ was then obtained by coupling with $O$-benzylhydroxylamine followed by hydrogenolysis.

The cis-aziridine hydroxamic acid $\mathbf{1 7}$ showed good inhibitory activity against several matrix metalloproteinases, in particular MMP-3 and MMP-9, with $\mathrm{IC}_{50}$ 's of $164 \mathrm{nM}$ and $83 \mathrm{nM}$, respectively [63].

\section{Methyl jasmonates and dihydrojasmonates (2001)}

The jasmonates, which comprise of methyl jasmonate (11) and the corresponding jasmonic acid, are important cellular regulators in plants. They participate in various developmental processes and defence mechanisms against biotic and abiotic stresses [114]. Originally isolated from Jasminum grandiflorum, the plant scent methyl jasmonate has found to be distributed ubiquitously in the plant kingdom. The unnatural analogue methyl dihydrojasmonate (150) possesses important olfactory properties and has become a major aroma chemical with a wide range of uses, mainly in fragrances (Scheme 18).

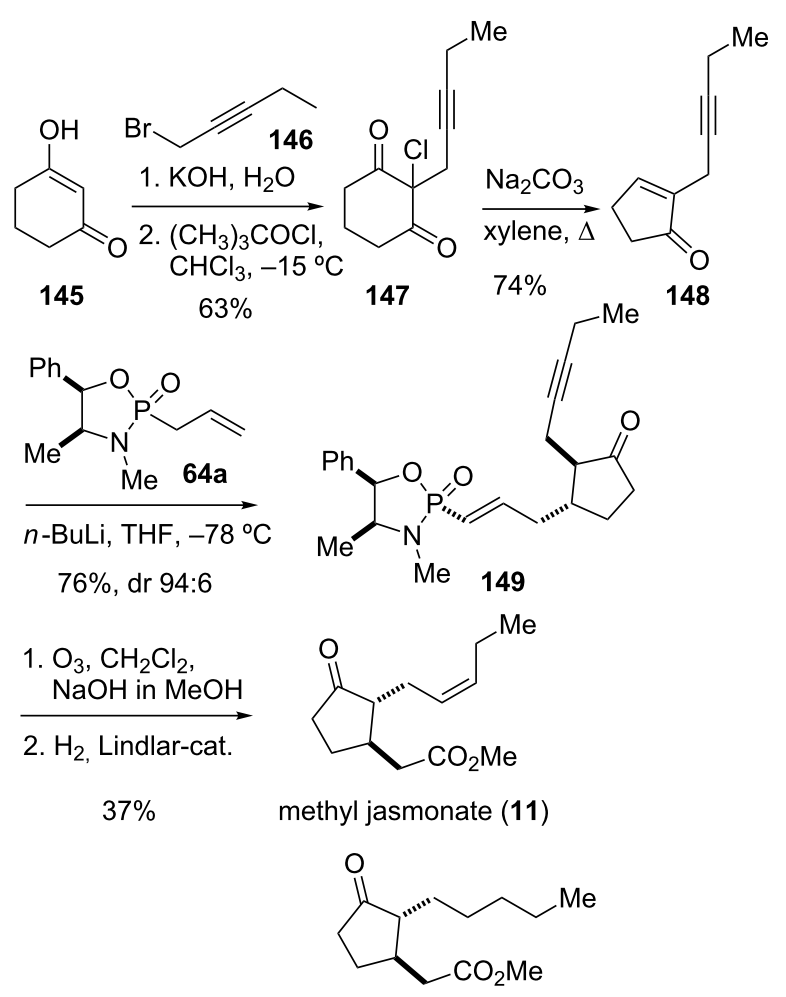

methyl dihydrojasmonate (150)
Hailes and co-workers were interested in developing a short synthetic route to both enantiomers of methyl jasmonate and methyl dihydrojasmonate, respectively [48]. To this end, they investigated the conjugate addition of chiral 2-propenylphosphonamides such as $\mathbf{6 4 a}$, derived from $(1 R, 2 S)$-ephedrine, to $\alpha$-substituted cyclopentenones. The required precursor for the synthesis of methyl jasmonate (11), 2-(2-pentynyl)-2-cyclopentene-1-one (148) was prepared by a known sequence [115] starting from 1,3-cyclohexanedione (145) (Scheme 18). Addition to 1-bromo-2-pentyne (146) followed by chlorination gave chlorodiketone 147. The latter was then treated with sodium carbonate in boiling xylene to afford cyclopentenone $\mathbf{1 4 8}$, presumably via decarbonylation of a cyclopropanone intermediate. Addition of the lithium anion of chiral phosphonamide 64a at low temperature produced adduct $\mathbf{1 4 9}$ in good yield and diastereoselectivity. Cleavage of the phosphonamide auxiliary from 149 was achieved by ozonolysis in the presence of sodium hydroxide and methanol to give the corresponding methyl ester. The final reduction of the alkyne was carried out using the Lindlar catalyst to yield methyl jasmonate (11). Methyl dihydrojasmonate (150) was also synthesized using phosphonamide reagent 64a, while replacing 148 with commercially available 2-pentyl-2-cyclopenten-1-one [48].

\section{Nudiflosides A and D (2006)}

Extracts from Jasminum nudiflorum have been used as folk medicine in China for the treatment of inflammation and traumatic bleeding. The leaves and stems of this plant contain oleoside-type secoiridoid glucosides with structurally interesting tetrasubstituted cyclopentanoid monoterpene units [116]. Two representative examples of these glycosides are nudifloside A (151) and D (13), which share a common subunit (Figure 8) [116-118]. The first total synthesis of nudiflosides A and D was achieved by Hanessian and co-workers, which aimed at<smiles>[R]OC1CC([M])[C@H](COC(=O)CC2C(C(=O)OC)=CO[C@@H](OC3CCCCC3)[C@@H]2C(C)CO)[C@H]1C</smiles>

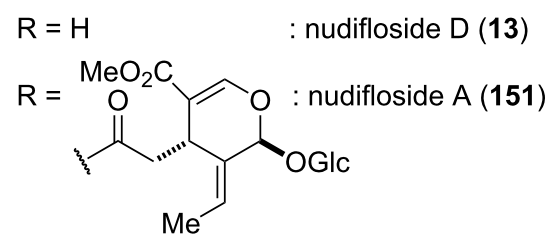

Figure 8: Structures of nudiflosides A (137) and D (13) [49]. 
confirming their proposed structural and stereochemical assignment (Scheme 19) [49].

The correct installation of the stereocenters of the cyclopentane subunit 159 was dependent on the stereocontrolled Michael addition of the anion generated from crotyl phosphonamide $\mathbf{2 8 f}$, which set three contiguous stereocenters in one step. Thus, addition of the Li anion of $\mathbf{2 8 f}$ to cyclopentenone $\mathbf{1 5 3}$ gave adduct 154 as a single diastereomer on a gram scale. Cleavage of the chiral auxiliary through ozonolysis followed by protection of the side chain as TBDPS ether afforded cyclopentanone $\mathbf{1 5 5}$. Saegusa-Ito oxidation followed by epoxidation of the formed enone gave 156 as the major isomer (dr 9:1). Regioselective reductive opening of the epoxide with $\mathrm{Na}\left[\mathrm{PhSeB}(\mathrm{OEt})_{3}\right]$ produced hydroxy ketone $\mathbf{1 5 7}$, which was then converted into the exo-methylene analogue $\mathbf{1 5 8}$ with Nysted's reagent. Cleavage of the benzyl ether and stereocontrolled reduction of the olefin in the presence of Crabtree's catalyst afforded a single isomer, presumably due to a directing effect of the adja- cent hydroxy group. Final removal of the TBDPS protecting group gave cyclopentane triol 159, which was esterified with varying equivalents of oleoside monomethyl ester peracetate 160 under Yamaguchi conditions $[119,120]$ to give nudiflosides A (151) and D (13), respectively, thereby completing the synthesis and confirming the proposed stereochemistry [49].

\section{Glutamate metabotropic receptor agonists (2000,} 2007)

The metabotropic glutamate receptors (mGluRs) are members of the vast family of G-protein coupled receptors which are expressed throughout the central nervous system. They consist of at least eight sub-types, which are divided into three groups I-III. Through binding of glutamate 161 (Figure 9), the most abundant excitatory neurotransmitter in the mammalian central nervous system, the mGluRs are activiated and participate in the regulation of synaptic transmission and neuronal excitability through a metabotropic process. There is ongoing interest in mGluRs as drug targets, and the therapeutic potential of mGluR

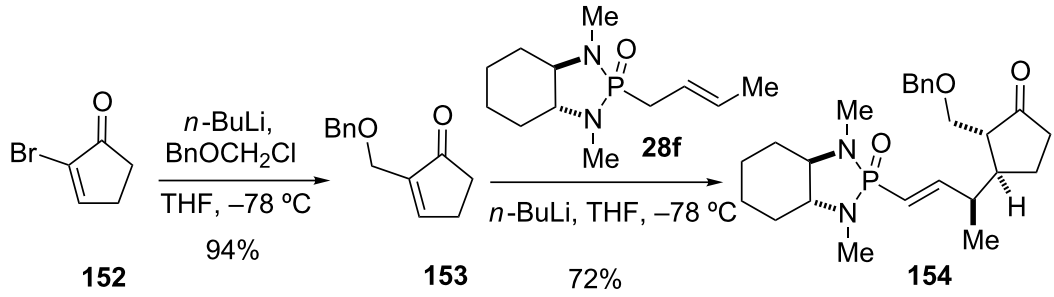
152 153 $72 \%$ 154

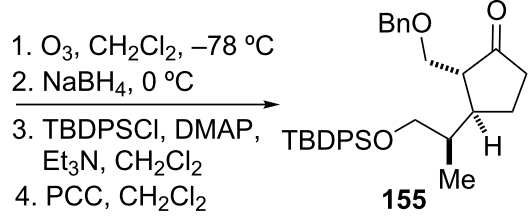
$78 \%$

Nysted's reagent $\mathrm{Zn}\left(\mathrm{CH}_{2} \mathrm{ZnBr}\right)_{2} \cdot \mathrm{THF}$ $\mathrm{TiCl}_{4}, \mathrm{THF}$ $74 \%$

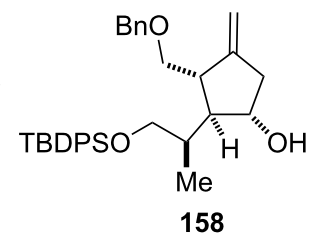<smiles>C/C=C1\C(O[Ge])OC=C(C(=O)O)C1CC(=O)O</smiles>
157 158 $50 \%$ $31-37 \%$

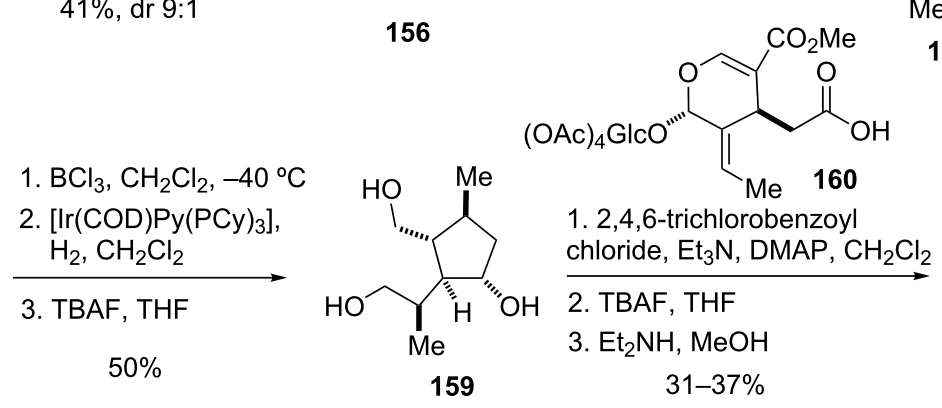
1. LDA, TMSCl,
$\mathrm{Pd}(\mathrm{OAc})_{2}, \mathrm{THF}$ 156<smiles>[R]C[C@H]1C(C)CC([R])[C@H]1C(C)CO</smiles>

nudifloside A (151)<smiles>[R]C[C@H]1C(C)C[C@@H](O)[C@H]1C(C)CO</smiles>

nudifloside D (13)<smiles>[R]=[C][C@H]1OC=C(C(C)=O)[C@@H](CC(=O)I)/C1=C/C</smiles> 
<smiles>N[C](CCC(=O)O)C(=O)O</smiles>

L-glutamic acid (161)<smiles>[R]C1C(C(=O)O)[C@H]1C(N)C(=O)O</smiles>

$\mathrm{R}=\mathrm{CO}_{2} \mathrm{H}:$ DCG-IV (162)

$\mathrm{R}=\mathrm{Ph}: \quad \mathrm{PCCG}-4(\mathbf{1 6 3})$<smiles>N[C@@H](C(=O)O)C1C(PO)[C@@H]1P</smiles>

21

Figure 9: L-glutamic acid (161) and constrained analogues [57,124].

ligands for the treatment of CNS disorders and ailments such as Alzheimer's and Parkinson's disease, depression, anxiety, and schizophrenia is being validated $[121,122]$.

The discovery of group II mGluR agonist DCG-IV (162) (Figure 9) as a potent anticonvulsant and neuroprotective agent [123] had sparked interest in more efficient routes for its synthesis. Pellicciari and Marinozzi developed an asymmetric synthesis of DCG-IV (162) based on Hanessian's cyclopropanation protocol (Scheme 20) [57]. Thus, addition of the Li anion generated from 47 a to tert-butyl sorbate (106) afforded the cyclopropane $\mathbf{1 6 4}$ as a single diastereomer. Selective ozonolysis of the propenyl side chain followed by reductive work-up and subsequent conversion of the formed primary alcohol into the corresponding TBDMS ether provided intermediate $\mathbf{1 6 5}$. Removal of the chiral auxiliary and generation of the second carboxy moiety was then achieved by ozonolysis of $\mathbf{1 6 5}$ and ensuing esterification with diazomethane to give diacid ester 166. Treatment of the latter with TBAF cleaved the TBDMS ether and gave a lactone intermediate, which was then opened by morpholine to afford amide $\mathbf{1 6 7}$. The primary alcohol was then oxidized to the aldehyde under Swern conditions and submitted to a diastereoselective Strecker synthesis to install the amino acid moiety. Thus, condensation of the aldehyde with $(R)$ - $\alpha$-phenylglycinol followed by addition of trimethylsilylcyanide to the formed Schiff-base provided aminonitrile 168 as the major diastereomer ( $\mathrm{dr}$ 95:5). Oxidative cleavage of the phenylglycinol moiety with $\mathrm{Pb}(\mathrm{OAc})_{4}$ liberated the amino-functionality and hydrolysis of the amide and nitrile under acidic conditions finally gave DCG-IV (162) [57].

Pellicciari and co-workers also reported on the synthesis of other constrained bioisosteres of L-glutamic acid, such as PCCG-4 (163) (Figure 9) [124]. To this end, phosphonocyclopropylamino acid 21 was designed as an analogue to $\mathbf{1 6 3}$ by replacing a carboxylic acid with a phosphonic acid moiety [60,61]. The stereoselective synthesis of 21 relied on another cyclopropanation protocol developed by Hanessian and

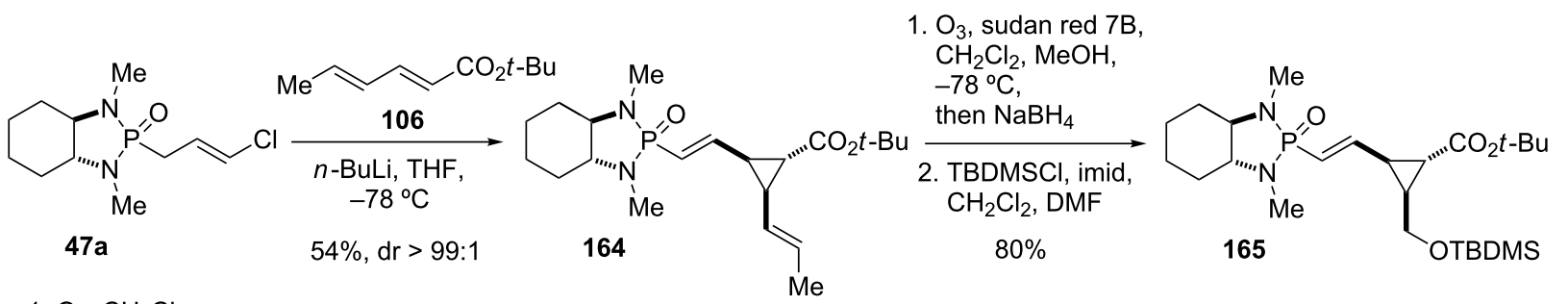

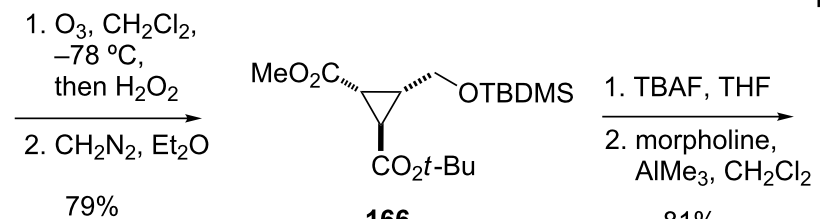
$79 \%$ 166<smiles>CCOC(=O)[C@@H]1[C@H](CO)[C@H]1C(=O)OCC(C)(C)C</smiles>

167
1. $(\mathrm{COCl})_{2}, \mathrm{DMSO}, \mathrm{NEt}_{3}$, $\mathrm{CH}_{2} \mathrm{Cl}_{2},-60^{\circ} \mathrm{C}$

2. (R)- $\alpha$-phenylglycinol, $\mathrm{MeOH}$, then TMSCN, $0^{\circ} \mathrm{C}$ $52 \%$<smiles>CCC(C)OC(=O)[C@@H]1[C@H](C(=O)N2CCOCC2)[C@H]1N[C@H](CO)c1ccccc1</smiles>

168

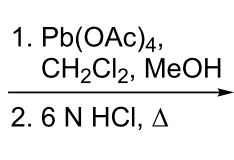

$60 \%$<smiles></smiles>

DCG-IV (162) 
co-workers [59]. Thus, conjugate addition of the anion of $\mathbf{2 8 d}$ to (E)-tert-butyl cinnamate (169) proceeded with excellent stereocontrol, and adduct $\mathbf{1 7 0}$ was isolated as a single diastereomer (Scheme 21).

Conversion of tert-butyl ester $\mathbf{1 7 0}$ into aldehyde $\mathbf{1 7 1}$ by a twostep protocol was followed by condensation with $(R)$ - $\alpha$-phenylglycinol and treatment of the formed Schiff base with trimethylsilylcyanide to afford $\alpha$-aminonitrile $\mathbf{1 7 2}$ as major isomer $(\mathrm{dr}>4: 1)$. Oxidative cleavage with $\mathrm{Pb}(\mathrm{OAc})_{4}$ liberated the amino functionality and hydrolysis of both the phosphonamide and nitrile groups under acidic conditions finally provided phosphonocyclopropylamino acid 21. This compound showed to be a group III mGluRs selective ligand with moderate potency as mGluR4 and mGluR6 agonist $\left(\mathrm{EC}_{50}\right.$ $59 \mu \mathrm{M}$ and $51 \mu \mathrm{M}$, respectively) $[60,61,124]$.

\section{Berkelic acid (2009)}

Berkelic acid (15) (Figure 10) is a spiroketal isolated from a fungus of the Penicillium species that grows in an unusual and harsh environment, Berkeley Pit Lake, an abandoned open-pit copper mine filled with acidic, metal-contaminated water [125]. The natural product shows moderate activity against MMP-3 and caspase-1, and high, selective activity toward ovarian cancer cell line OVCAR-3 with a $\mathrm{GI}_{50}$ of $91 \mathrm{nM}$. Both the relative configuration of the side chain as well as the absolute stereochemistry of the molecule was originally not assigned. The interesting biological profile in combination with the unknown stereochemical assignments made berkelic acid an attractive target for total synthesis, with the first one completed by Snider and co-workers [43].

The tetracyclic core of berkelic acid (15) was thought to be assembled through an oxa-Pictet-Spengler reaction from 2,6dihydroxybenzoic acid $\mathbf{1 7 3}$ and ketal aldehyde $\mathbf{1 7 4}$ as key building blocks (Figure 10). The 2,6-dihydroxybenzoic acid 173

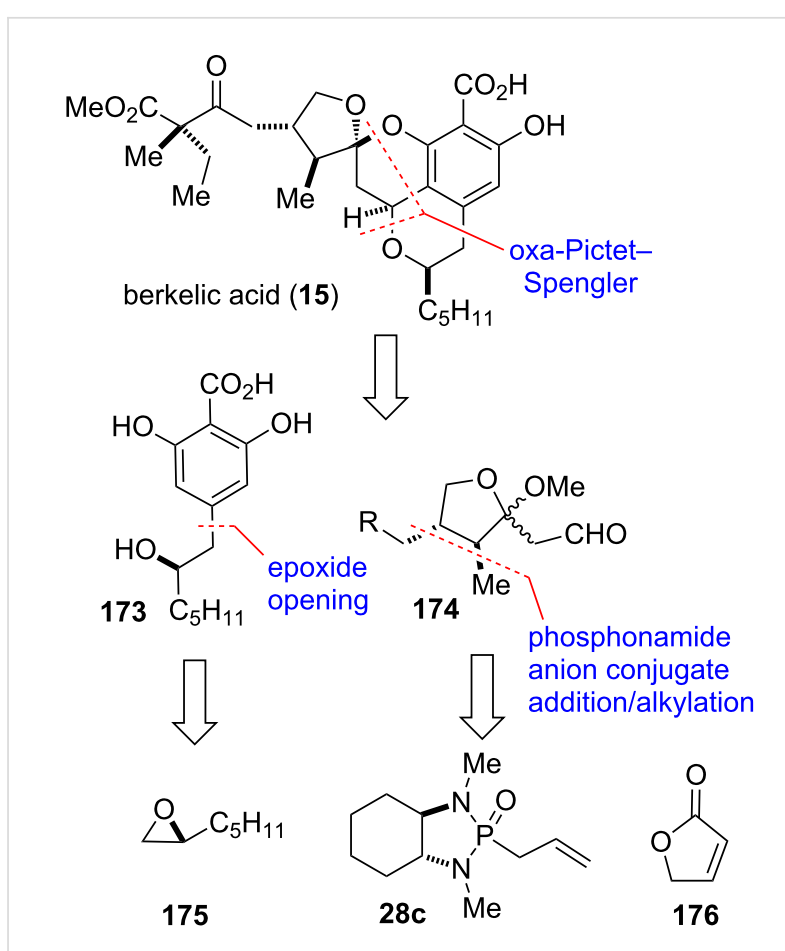

Figure 10: Key assembly strategy of berkelic acid (15) [43].

is accessible by opening of epoxide $\mathbf{1 7 5}$ as chiron with a suitable nucleophile. The ketal aldehyde 174 would be derived from butenolide $\mathbf{1 7 6}$ through a conjugate addition sequence employing phosphonamide $\mathbf{2 8 c}$, thereby setting two of the three stereocenters of the five-membered ring in a single step.

Thus, deprotonation of chiral phosphonamide 28c and addition of the anion to $2(5 H)$-furanone $(\mathbf{1 7 6})$ at $-100{ }^{\circ} \mathrm{C}$, followed by trapping with excess methyl iodide afforded adduct 177 with excellent selectivity $(\mathrm{dr}>95: 5)$ (Scheme 22). Ozonolysis with reductive work-up and ensuing protection of the formed hydroxy group as TPDPS ether provided lactone 178. Addition<smiles>CN1C2CCCCC2N(C)P1(=O)CCl</smiles>

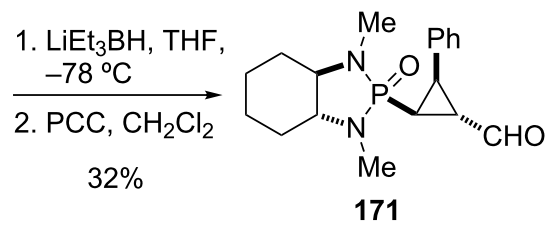

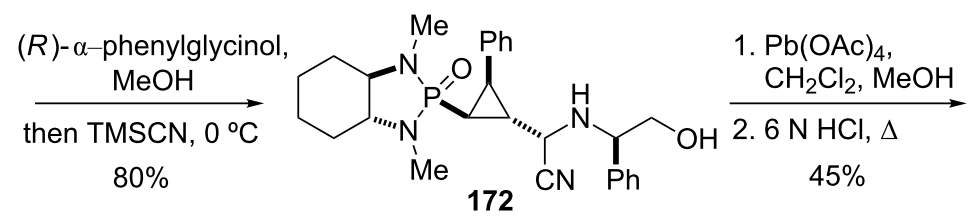<smiles>N[C@@H](C(=O)O)C1C(P)C1P(=O)(O)O</smiles> 
<smiles>C/C=C\CP1(=O)N(C)C2CCCCC2N1C</smiles>

28c

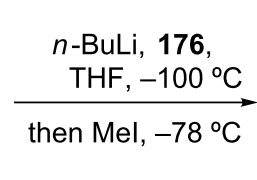

$73 \%, d r>95: 5$

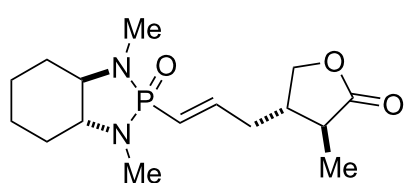

177

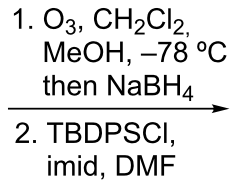

$52 \%$

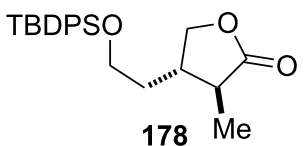

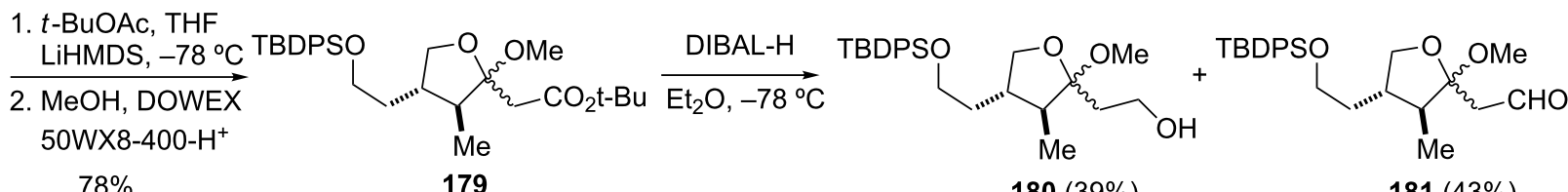

$78 \%$

179

$180(39 \%)$

$181(43 \%)$

$(\mathrm{COCl})_{2}, \mathrm{DMSO}, \mathrm{NEt}_{3},-78^{\circ} \mathrm{C} \uparrow$

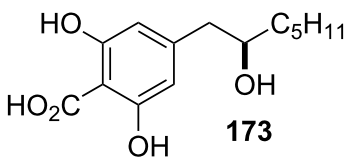

1. DOWEX $50 \mathrm{WX} 8-400-\mathrm{H}^{+}, \mathrm{MeOH}$

2. allyl bromide, $\mathrm{K}_{2} \mathrm{CO}_{3}$, DMF

3. TBAF, AcOH, THF

$45 \%$

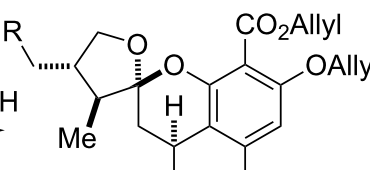<smiles>CCC(C)C(C(=O)O)N1BOC(=O)C1C(C)C</smiles>

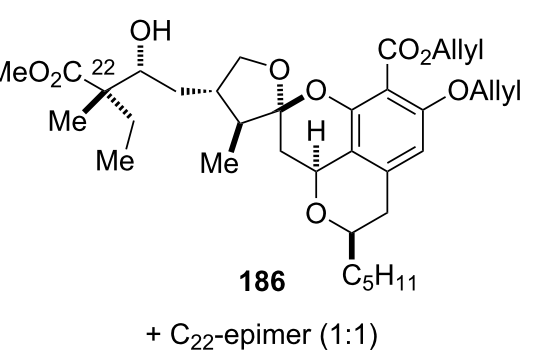

$80 \%$

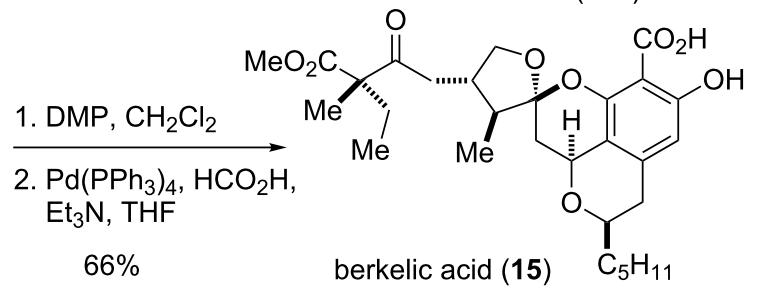

Scheme 22: Total synthesis of berkelic acid (15) [43]

of the enolate of tert-butyl acetate to $\mathbf{1 7 8}$ and ketal formation afforded 179. Reduction with DIBAL-H gave ketal aldehyde 181, which was then condensed with 2,6-dihydroxybenzoic acid 173 in a oxa-Pictet-Spengler reaction to form the tetracyclic core of berkelic acid. Treatment of the obtained tetracyclic salicylic acid with allyl bromide and desilyation with TBAF/AcOH provided 182. The primary alcohol of the side chain was oxidized with Dess-Martin periodinane (DMP) to give aldehyde 183. The latter was subsequently reacted with trimethylsilyl ketene acetal $\mathbf{1 8 4}$ in the presence of oxazaborolidinone $\mathbf{1 8 5}$ to afford aldol product $\mathbf{1 8 6}$ and the $\mathrm{C}_{22}$-epimer as only isomers in a 1:1 mixture. Dess-Martin oxidation and deprotection of both allyl groups with formic acid under palladium catalysis finally provided berkelic acid (15). Thus, total synthesis of both epimers established the relative configuration of the side chain at $\mathrm{C}_{22}$ which was previously unknown, as well as helped to determine the absolute stereochemistry of the molecule [43,126-132].

\section{Ambruticin S and jerangolid A (2010)}

The jerangolids [133,134] and the ambruticins [135-137] are part of two closely related families of linear polyketides with potent antifungal properties produced by a variety of myxobacteria. Besides the biochemical profile, the two families share common structural features and a common biosynthesis $[138,139]$. Among the five members of the jerangolid family, which may be considered as trunctated analogs of the ambruticins, jerangolid A is reported to be the most potent [133,134]. The ambruticin family currently consists of eight known members [140]. Since the "eastern" segment of jerangolid A (22) and ambruticin S (14) is identical, a synthetic strategy was considered for this segment that would allow for the total synthesis of both molecules (Figure 11) [27,28].

The strategy for the first synthesis of jerangolid A (22) is depicted in retrosynthetic format featuring dihydropyran $\mathbf{1 8 8}$, lactone 187 , and phosphonamide 189 a originating from the 


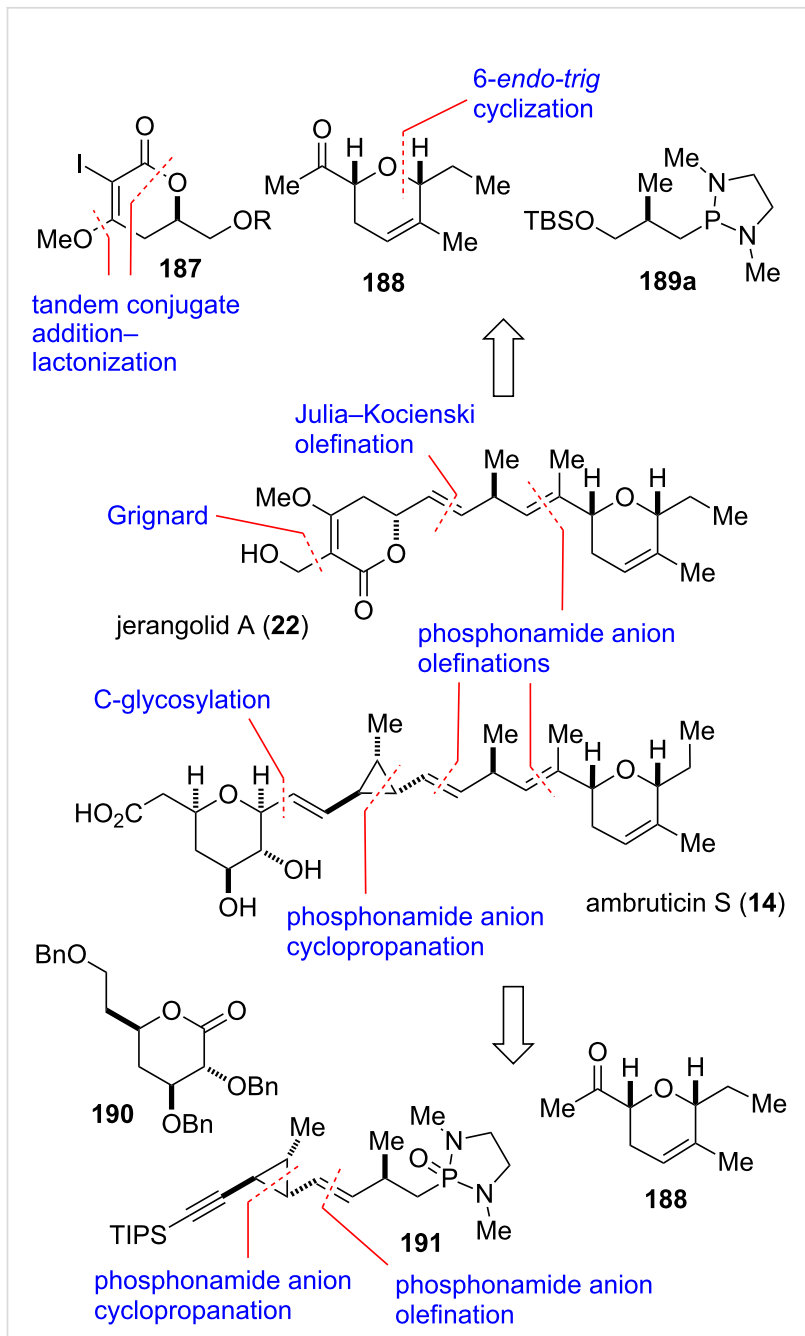

Figure 11: Key assembly strategy of jerangolid A (22) and ambruticin $S(14)[27,28]$.

Roche ester (Figure 11) [27]. Lactone 187 ring was thought to be formed from addition of ethyl propiolate to $(S)$-glycidol, and ensuing conjugate addition of methanol and lactonization. The second cyclic building block, syn-dihydropyran 188, could be synthesized by a highly diastereoselective 6-endo-trig cyclization of an allylic 1,3-diol, which was developed by Hanessian and co-workers [141]. The required allylic 1,3-diol would also be accessed from $(S)$-glycidol. The assembly of the two cyclic building blocks and the Roche ester derived middle fragment under formation of the trans-double bonds would utilize phosphonamide and sulfone anion coupling strategy, respectively. A similar strategy was employed for the assembly of ambruticin S (14). Disconnection at logical sites led to lactone 190 derived from D-glucose, dihydropyran methyl ketone 188, and phosphonamide 191 as advanced intermediates [28]. Building block 191 and three of its four stereocenters would be constructed via phosphonamide-mediated olefination and cyclopropanation reactions [51-55]. The remaining stereocenter would originate from Roche ester as a readily available chiron.

The final steps in the assembly of jerangolid A (22) are shown in Scheme 23. The required cyclic phosphonamide reagent 189 for the olefination of methyl ketone $\mathbf{1 8 8}$ was obtained from alkylation of 1,3-dialkyl-2-oxo-1,3,2-diazaphospholidines 193a-c [69-71] with iodide 192. The latter was prepared from $(S)$-Roche ester in a three step sequence. Coupling of methyl ketone 188 with phosphonamides 189a-c afforded separable mixtures of $E / Z$ isomers of TBS ether 197, gratifyingly with the desired $E$-isomer as the major product (Table 2).

$$
\text { 2. }
$$

Scheme 23: Final assembly steps in the total synthesis of jerangolid $A$ [27].

The reaction conditions, the steric nature of the phosphonamide $\mathrm{N}$-substituents as well as its absolute configuration had a significant impact on the stereoselectivity of the olefination. Thus, treatment of methyl ketone $\mathbf{1 8 8}$ with dimethyl phosphonamide 189a afforded the corresponding olefin 197 in a $3: 1 \mathrm{E} / \mathrm{Z}$ ratio (Table 2, entry 1). Equilibrating the reaction mixture at ambient temperature before adding acetic acid helped to improve the $E / Z$ ratio to $6: 1$ (Table 2, entry 2). The $E / Z$ selectivity could further be enhanced by increasing the steric demand of the phosphonamide substituents. Replacing methyl with isopropyl improved the selectivity from $3: 1$ to $13: 1$, albeit to the 
Table 2: Olefination of ketone 188 employing cyclic phosphonamides 189 [27]. ${ }^{a}$

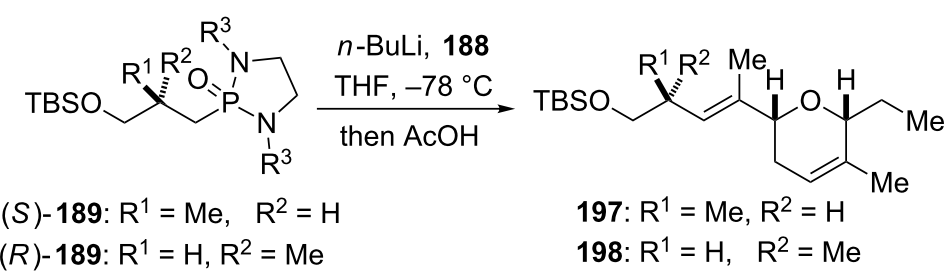

(S)-189: $\mathrm{R}^{1}=\mathrm{Me}, \mathrm{R}^{2}=\mathrm{H}$

198: $R^{1}=H, \quad R^{2}=M e$

\begin{tabular}{ccccc}
\hline Entry & Phosphonamide & Product & Yield (\%) \\
\hline $\mathbf{1}$ & $(R)-189 \mathrm{a}: \mathrm{R}^{3}=\mathrm{Me}$ & 197 & 57 & $3: 1$ \\
2 & $(R)-189 \mathrm{a}: \mathrm{R}^{3}=\mathrm{Me}$ & 197 & 62 & 38 \\
3 & $(R)-189 \mathrm{~b}: \mathrm{R}^{3}=\mathrm{Et}$ & 197 & 20 & $5: 1$ \\
$\mathbf{4}$ & $(R)-189 \mathrm{c}: \mathrm{R}^{3}=\mathrm{iPr}$ & 197 & 63 & $13: 1$ \\
5 & $(S)-189 \mathrm{a}: \mathrm{R}^{3}=\mathrm{Me}$ & 198 & $19: 1$ & \\
\hline
\end{tabular}

aReaction conditions: $189, n$-BuLi, THF, $-78^{\circ} \mathrm{C}, 1 \mathrm{~h} ; \mathbf{1 8 8},-78{ }^{\circ} \mathrm{C}, 1 \mathrm{~h}$; then $\mathrm{AcOH}(\mathrm{xs}),-78{ }^{\circ} \mathrm{C}$ to rt. ${ }^{\mathrm{b}} \mathrm{Addition}$ of $\mathrm{AcOH}$ at rt.

expense of lower conversion and increased recovery of starting material (Table 2, entry 1 and 4). Remarkably, the (S)-enantiomer of dimethyl phosphonamide 189a furnished an excellent $E / Z$ ratio of 19:1 in the olefination of $\mathbf{1 8 8}$ to afford diastereomer 198 (Table 2, entry 5).

Deprotection of TBS ether 197 with TBAF provided alcohol 194 which was then transformed into known phenyltetrazole (PT) sulfone 195 [142,143] through Mitsunobu reaction with 1-phenyltetrazole-5-thiol (PTSH), followed by oxidation of the intermediate sulfide. Coupling of the lactone building block in form of aldehyde 196 with the fully elaborated PT-sulfone 195 provided the corresponding olefin with the correct double-bond geometry in moderate yield and excellent selectivity $(E / Z>25: 1)$. Lastly, cleavage of the TBS ether under mild acidic conditions afforded jerangolid A (22) [27,143,144].

The synthesis of ambruticin S commenced with the 1,4-conjugate addition of the anion of chiral trans-chlorallyl phosphonamide ent-47a to tert-butyl crotonate (199) to give cyclopropane $\mathbf{2 0 0}$ as a single diastereomer with the desired relative and absolute stereochemistry (Scheme 24) [28]. Removal of the chiral auxiliary by oxidative cleavage of the olefin furnished aldehyde 201, which was coupled with phosphonamide 189a to afford olefin 202 in good yield and excellent selectivity $(E / Z>25: 1)$. The latter was then converted into alkyne 205 via DIBAL-H reduction of the tert-butyl ester moiety followed by Swern oxidation to give aldehyde 203, and treatment with the Ohira-Bestmann reagent 204 [145,146]. Protection of the alkyne $\mathrm{CH}$ as its TIPS-derivative, chemoselective removal of the TBS group using CSA and transformation of the obtained primary alcohol with iodine and $\mathrm{PPh}_{3}$ gave iodide 206. The latter was then converted into phosphonamide 191 by treatment with the lithium anion of 1,3-dimethyl-2-oxo-1,3,2-diazaphospholidine (193a). Coupling with methyl ketone 188 was performed in a similar fashion as described for jerangolid A. Thus, deprotonation of phosphonamide 191 with $n$-butyllihium and treatment with methyl ketone $\mathbf{1 8 8}$ followed by addition of acetic acid provided triene $\mathbf{2 0 7}$ as the desired major isomer with moderate selectivity $(E / Z$ 6:1). Treatment of $\mathbf{2 0 7}$ with TBAF liberated alkyne 208, which was coupled with lactone $\mathbf{1 9 0}$ in a two-step sequence to give the desired syn-dihydrofuran 209 as a single diastereomer. Next, cleavage of the three benzyl ether moieties without reducing any of the double-bonds was achieved using lithium 4,4-di-tert-butylbiphenylide (LiDBB) to deliver alkyne 210. The homopropargylic system was reduced with sodium bis(2-methoxyethoxy)aluminum hydride to afford the corresponding olefin with good selectivity $(E / Z>10: 1)$. Finally, selective oxidation of the primary hydroxy group was achieved using a method that was chosen before by Jacobsen for the same transformation [147]. Thus, treatment of the intermediate triol with oxygen under platinum catalysis efficiently oxidized the primary alcohol group to the carboxylic acid without affecting the two secondary hydroxy groups and provided (+)-ambruticin S (14) [28,142,147-151].

\section{Estrone (2010)}

Estrone (12), an aromatized C18 steroid with a 3-hydroxy group and a 17-ketone, is a member of the estrogenic hormones, which also include estriol and estradiol. In humans, it is produced primarily by the cyclic ovaries, placenta, and the adipose tissue of men and postmenopausal women [152].

A classic problem in steroid synthesis is the selective formation of the trans-fused ring junction. A common strategy to circumvent this issue is to employ a cyclization strategy that 


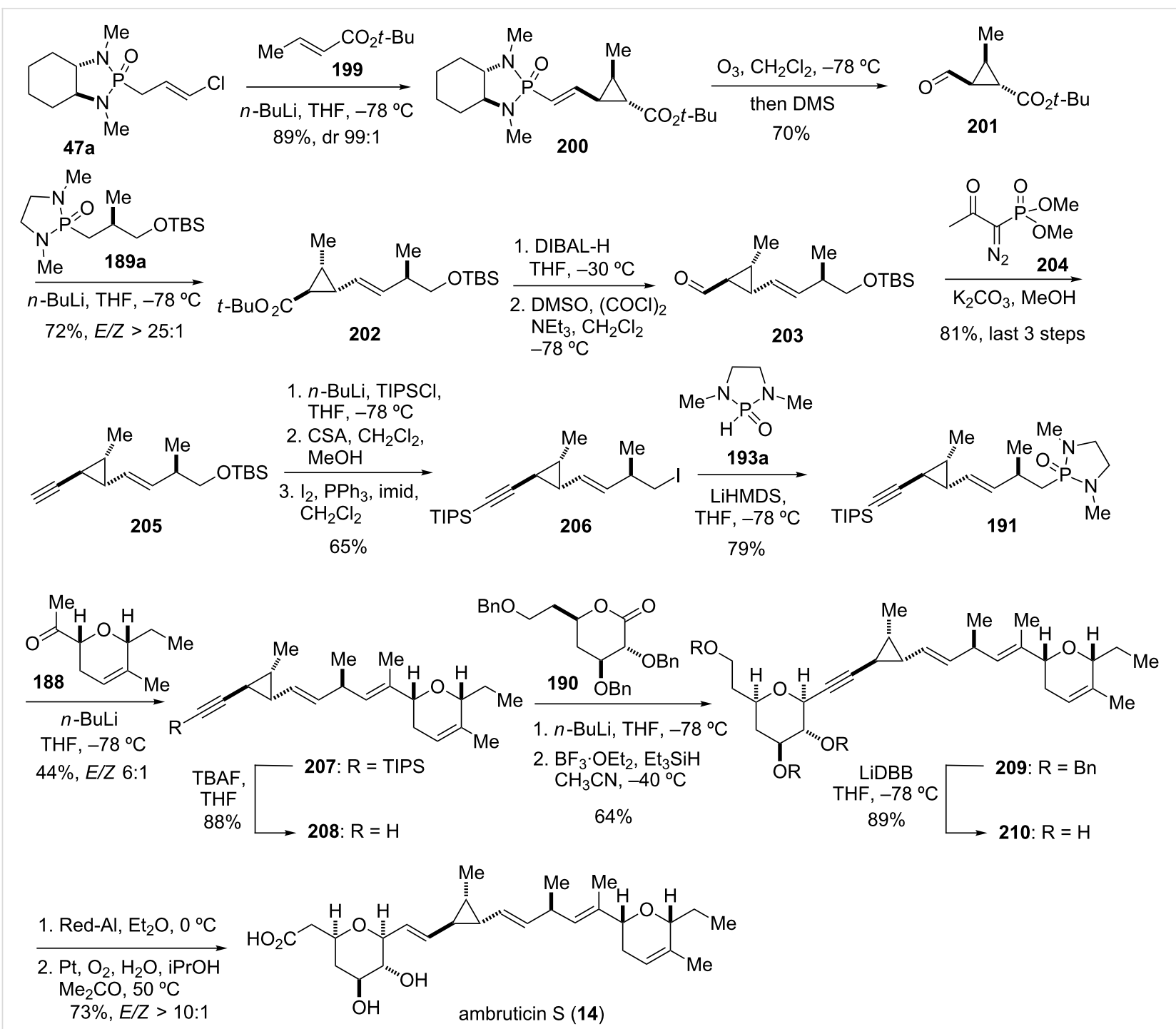

Scheme 24: Key assembly steps in the total synthesis of ambruticin S (14) [28].

commences from a D-ring precursor already containing the correct stereochemistry at the future CD ring junction $[153,154]$. Linclau and co-workers developed this concept further and a general steroid construction strategy based on the formation of a D-ring template that contains the correct configuration of three stereocenters $\mathrm{C} 8, \mathrm{C} 13$ and $\mathrm{C} 14$ with suitable functionalization for the following $\mathrm{C}$ - and B-ring cyclizations (Figure 12). The applicability of this approach to steroid synthesis was validated using estrone as target [44]. A key requirement for the strategy was a highly diastereo- and enantioselective formation of the D-ring intermediate $\mathbf{2 1 1}$ and flexibility in introducing different $R^{1}$ and $R^{2}$ groups to enable the synthesis of diverse steroids targets. Intermediate $\mathbf{2 1 1}$ was envisioned to come from a one-pot process involving the conjugate addition of a chiral phosphonamide anion to cyclopentenone $\mathbf{4 8}$ followed by an alkylation to introduce $\mathrm{R}^{1}$. Furthermore, the obtained vinylic phosphonamide was thought to be an excellent reactive handle for the following $\mathrm{C}$-ring cyclization.

The synthesis of the required $Z$-allylic phosphonamide 216 began from dibromide $\mathbf{2 1 3}$ by benzylic displacement with allenylmagnesium bromide followed by reaction with paraformaldehyde to give propargylic alcohol 214 (Scheme 25). Alkyne reduction was performed with $\mathrm{Zn}$ and dibromoethane to give selectively the corresponding cis-alkene. The $\mathrm{Zn}$ /dibromoethane system proved to be more reliable for this reduction than using hydrogen and poisoned Pd-catalysts. Chlorination with hexachloroacetone gave allylic chloride 215, which was then converted to phosphonamide $\mathbf{2 1 6}$ via an Arbuzov reaction with phospholane 60. Deprotonation of 216 and addition to cyclopentenone $\mathbf{4 8}$ followed by alkylation with allyl bromide afforded adduct $\mathbf{2 1 7}$ as a single diastereomer. 


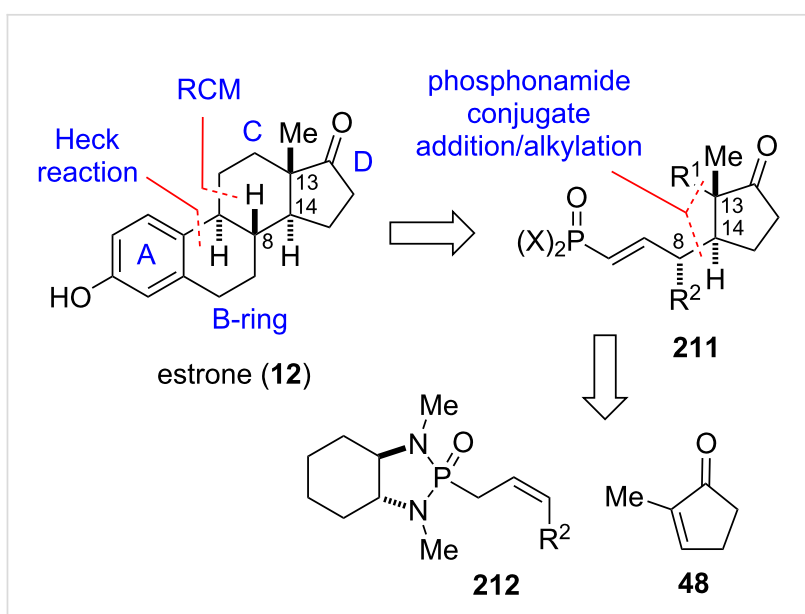

Figure 12: General steroid construction strategy based on conjugate addition of $\mathbf{2 1 2}$ to cyclopentenone $\mathbf{4 8}$, exemplified with estrone (12) [44].

With key intermediate $\mathbf{2 1 7}$ in hand, the B and C ring systems were then constructed by two subsequent cyclizations. Thus, treatment of the phosphonic acid obtained from acid hydrolysis of 217 with Hoveyda-Grubbs II catalyst afforded trans- hydrindene 218, with the $\Delta 9,11$ double bond perfectly positioned for the subsequent Heck B-ring closure. Cyclization product 220 was then obtained in quantitative yield by treatment of 218 with catalytic amounts of palladacyle 219 at elevated temperature, albeit with the undesired $9 \beta$-configuration. Inversion of the $\mathrm{C} 9$ stereocenter and reduction of $\mathbf{2 2 0}$ was achieved by an isomerization/hydrogenation process using $\mathrm{Pd} / \mathrm{C}$ and cyclohexadiene, which produced 221 and its C9 epimer 9ק-221 in a 7:3 mixture. Separation of the desired isomer by crystallization and cleavage of the methyl ether finally gave estrone (12). Three of the four stereocenters of estrone [155163] were set in a single conjugate addition and enolate alkylation reaction with excellent stereocontrol [44].

\section{Conclusion}

In this review we summarized a substantial volume of work dealing with the preparation, reactivity, and utility of cyclic phosphonamides as versatile reagents for the asymmetric synthesis of a variety of acyclic and carbocyclic chiral non-racemic compounds. The focus was placed on enantiomerically pure pentacovalent $C_{2}$-symmetrical phosphonamides, whose stabilized anions have been used as nucleophilic reagents toward

$$
\text { (12) }
$$

$\mathrm{Nal}, \mathrm{PhMe}, \Delta$ $85 \%$

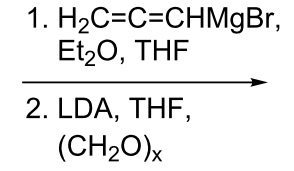
$78 \%$<smiles>COc1ccc(Br)c(CCC#CCO)c1</smiles>

1. $\mathrm{Zn}, \mathrm{EtOH}$,<smiles>COc1ccc(Br)c(CC/C=C\CCl)c1</smiles>

$\mathrm{OH}$ $92 \%, E / Z 2: 98$

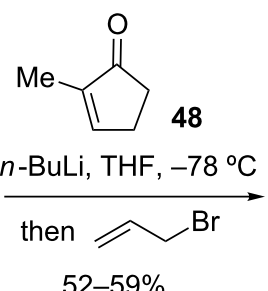<smiles>CCCCCCC(C)OC</smiles><smiles>C=CC[C@]1(O)C(=O)CC[C@H]1/C(C=CP(C)N(C)C)=C\CCc1cc(OC)ccc1Br</smiles>

215<smiles>COc1ccc(Br)c(CC/C=C\CP(=O)(Cc2ccccc2)N(C)C2CCCCC2N(C)C)c1</smiles>

216
$52-59 \%$

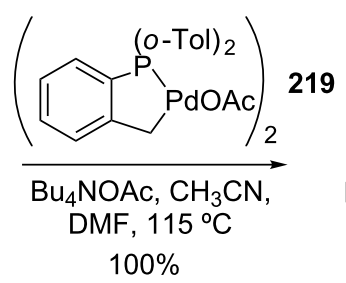
$00 \%$

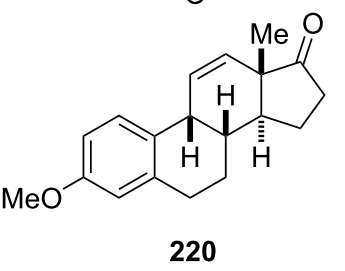

$$
\begin{gathered}
\frac{\text { 1. } \mathrm{HCl}, \mathrm{THF}, 65^{\circ} \mathrm{C}}{\text { 2. Hoveyda-Grubbs II }} \\
(35 \mathrm{~mol} \%), \text { PhMe, } 7 \\
54 \% \\
\\
\mathrm{Pd} / \mathrm{C}, \\
\frac{\text { cyclohexadiene }}{\mathrm{EtOH}}
\end{gathered}
$$
(35 mol \%), PhMe, $70^{\circ} \mathrm{C}$ $98 \%, 9 \beta / 9 \alpha 3: 7$<smiles>[Z16]c1cc(OC)ccc1CC[C@H]1C=CC[C@]2(C)C(=O)CC[C@H]12</smiles>
218

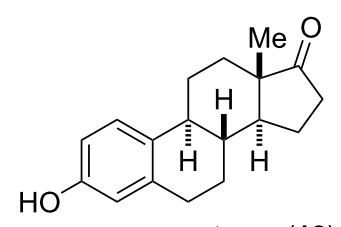

estrone (12) 
electrophiles in a variety of applications. Especially useful among others are tandem conjugate additions to $\alpha, \beta$-unsaturated carbonyl substrates followed by alkylation of the resulting enolates to give diastereomerically enriched acyclic, carbocyclic, and azacyclic molecules harboring as many as three contiguous stereogenic centers. These have been useful starting materials for the synthesis of a number of natural products and biologically active molecules such as enzyme inhibitors, bioisosteres, and receptor agonists to mention a few. Although the initial products must be oxidatively cleaved to obtain the corresponding aldehydes, thereby sacrificing the original phosphonamide portion, the benefits are in the highly functionalized products that are obtained, many of which are not easily attainable by other means. The methods are also of great utility for the stereocontrolled synthesis of the medicinally important $\alpha$-substituted phosphonic acids in the case of alkyl halides as electrophiles. The utility of chiral non-racemic phosphonamides in organic synthesis extends beyond their uses as mild carbon-based nucleophilic reagents for stereoselective alkylation, amination, Michael addition, cyclopropanation and aziridination reactions.

For example, diastereoselective $o$-metalation of ferrocenes was mediated by $(R, R)$ - $N, N^{\prime}$-dimethyl-1,2-diaminocyclohexane [164]. 2-Dimethylamino- $N, N$ '-diphenyl-1,3,2-diazaphospholidine is an excellent reagent for the conversion of alcohols to the corresponding crystalline 2-alkoxy- $N, N^{\prime}$-diphenyl-1,3,2diazophospholidines, simply by heating in toluene with elimination of dimethylamine [165]. The resulting products are excellent substrates for Arbuzov-type $\mathrm{S}_{\mathrm{N}} 2$ halogenations with methyl iodide or bromine as halogen sources. Related $C_{2}$-symmetrical diazaphospholidines can be used for the determination of enantiomeric excesses of chiral alcohols by ${ }^{1} \mathrm{H}$ NMR [166] and carboxylic acids [167].

The possibility to perform ring-closing metathesis reactions with $\alpha, \beta$-unsaturated phosphonic acids resulting from the hydrolysis of the initially formed phosphonamide, as in the recent synthesis of estrone [44], adds a new and exciting dimension to the utility of phosphonamides in asymmetric synthesis.

\section{Acknowledgements}

We thank NSERC for financial assistance.

\section{References}

1. Hanessian, S.; Delorme, D.; Beaudoin, S.; Leblanc, Y. J. Am. Chem. Soc. 1984, 106, 5754-5756. doi:10.1021/ja00331a070

2. Denmark, S. E.; Kim, J.-H. J. Org. Chem. 1995, 60, 7535-7547. doi:10.1021/jo00128a028

3. Denmark, S. E.; Chen, C.-T. J. Am. Chem. Soc. 1995, 117, 11879-11897. doi:10.1021/ja00153a009
4. Denmark, S. E.; Kim, J.-H. Can. J. Chem. 2000, 78, 673-688. doi:10.1139/v99-251

5. Hua, D. H.; Can-Yu-King, R.; McKie, J. A.; Myer, L. J. Am. Chem. Soc. 1987, 109, 5026-5029. doi:10.1021/ja00250a047

6. Hua, D. H.; Chen, J. S.; Sha, S.; Wang, H.; Roche, D.; Bharathi, S. N.; Chan-Yu-King, R.; Robinson, P. D.; Iguchi, S. Synlett 1992, 817-820. doi:10.1055/s-1992-21503

7. Sting, M.; Steglich, W. Synthesis 1990, 132-134 doi:10.1055/s-1990-26810

8. Giovenzana, G. B.; Pagliarin, R.; Palmisano, G.; Pilati, T.; Sisti, M. Tetrahedron: Asymmetry 1999, 10, 4277-4280. doi:10.1016/S0957-4166(99)00455-3

9. Cravotto, G.; Giovenzana, G. B.; Pagliarin, R.; Palmisano, G.; Sisti, M. Synth. Commun. 2001, 31, 1013-1020. doi:10.1081/SCC-100103530

10. Hanessian, S. J. Org. Chem. 2012, 77, 6657-6688. doi:10.1021/jo300902m

11. Denmark, S. E.; Stadler, H.; Dorow, R. L.; Kim, J.-H. J. Org. Chem. 1991, 56, 5063-5079. doi:10.1021/jo00017a016

12. Denmark, S. E.; Marlin, J. E.; Rajendra, G. J. Org. Chem. 2013, 78, 66-82. doi:10.1021/jo301919e

13. Molt, O.; Schrader, T. Synthesis 2002, 2633-2670. doi:10.1055/s-2002-35977

14. Bennani, Y. L.; Hanessian, S. Chem. Rev. 1997, 97, 3161-3196. doi:10.1021/cr9407577 See for a review.

15. Corey, E. J.; Cane, D. E. J. Org. Chem. 1969, 34, 3053-3057. doi:10.1021/jo01262a058

16. Patois, C.; Savignac, P. Tetrahedron Lett. 1991, 32, 1317-1320. doi:10.1016/S0040-4039(00)79655-9

17. Patois, C.; Savignac, P. Synlett 1991, 517-519. doi:10.1055/s-1991-20785

18. Hanessian, S.; Bennani, Y. L.; Leblanc, Y. Heterocycles 1993, 35, 1411-1424. doi:10.3987/COM-93-S(T)145

19. Corey, E. J.; Kwiatkowsky, G. T. J. Am. Chem. Soc. 1968, 90, 6816-6821. doi:10.1021/ja01026a045

20. McMurry, J. E.; von Beroldingen, L. A. Tetrahedron 1974, 30 , 2027-2032. doi:10.1016/S0040-4020(01)97334-X

21. Denmark, S. E.; Amburgey, J. J. Am. Chem. Soc. 1993, 115, 10386-10387. doi:10.1021/ja00075a075

22. Hanessian, S.; Beaudoin, S. Tetrahedron Lett. 1992, 33, 7655-7658. doi:10.1016/0040-4039(93)88008-7

23. Hanessian, S.; Beaudoin, S. Tetrahedron Lett. 1992, 33, 7659-7662. doi:10.1016/0040-4039(93)88009-8

24. Hanessian, S.; Fu, J.-M.; Tu, Y.; Isono, K. Tetrahedron Lett. 1993, 34, 4153-4156. doi:10.1016/S0040-4039(00)60515-4

25. Hanessian, S.; Fu, J.-M.; Chiara, J.-L.; Di Fabio, R. Tetrahedron Lett. 1993, 34, 4157-4160. doi:10.1016/S0040-4039(00)60516-6

26. Hanessian, S.; Fu, J.-m. Can. J. Chem. 2001, 79, 1812-1826. doi:10.1139/v01-171

27. Hanessian, S.; Focken, T.; Oza, R. Org. Lett. 2010, 12, 3172-3175. doi:10.1021/ol101103q

28. Hanessian, S.; Focken, T.; Mi, X.; Oza, R.; Chen, B.; Ritson, D.; Beaudegnies, R. J. Org. Chem. 2010, 75, 5601-5618. doi:10.1021/jo100956v

29. Hanessian, S.; Bennani, Y. L.; Delorme, D. Tetrahedron Lett. 1990, 31, 6461-6464. doi:10.1016/S0040-4039(00)97091-6

30. Bennani, Y. L.; Hanessian, S. Tetrahedron 1996, 52, 13837-13866. doi:10.1016/0040-4020(96)00829-0

31. Hanessian, S.; Bennani, Y. L. Tetrahedron Lett. 1990, 31, 6465-6468. doi:10.1016/S0040-4039(00)97092-8 
32. Kukhar, V. P.; Hudson, H. R. Aminophosphonic and Aminophosphinic Acids: Chemistry and Biological Activity; John Wiley \& Sons: Chichester, 2000.

33. Ma, J.-A. Chem. Soc. Rev. 2006, 35, 630-636. doi:10.1039/b517100h

34. Naydenova, E. D.; Todorov, P. T.; Troev, K. D. Amino Acids 2010, 38, 23-30. doi:10.1007/s00726-009-0254-7

35. Hanessian, S.; Bennani, Y. L. Synthesis 1994, 1272-1274. doi:10.1055/s-1994-25679

36. Lawrence, R. M.; Biller, S. A.; Dickson, J. K., Jr.; Logan, J. V. H.; Magnin, D. R.; Sulsky, R. B.; DiMarco, J. D.; Gougoutas, J. Z.; Beyer, B. D.; Taylor, S. C.; Lan, S.-J.; Ciosek, C. P., Jr.; Harrity, T. W.; Jolibois, K. G.; Kunselman, L. K.; Slusarchyk, D. A. J. Am. Chem. Soc. 1996, 118, 11668-11669. doi:10.1021/ja962505o

37. Hanessian, S.; Gomtsyan, A.; Payne, A.; Hervé, Y.; Beaudoin, S. J. Org. Chem. 1993, 58, 5032-5034. doi:10.1021/j000071a004

38. Hanessian, S.; Gomtsyan, A. Tetrahedron Lett. 1994, 35, 7509-7512. doi:10.1016/S0040-4039(00)78330-4

39. Hanessian, S.; Gomtsyan, A.; Malek, N. J. Org. Chem. 2000, 65, 5623-5631. doi:10.1021/jo000388g

40. Hanessian, S.; Griffin, A. M.; Cantin, L.-D. Chirality 2000, 12, 342-345. doi:10.1002/(SICI)1520-636X(2000)12:5/6<342::AID-CHIR7>3.0.CO;2 $-Y$

41. Paquette, L. A.; Wang, T.-Z.; Pinard, E. J. Am. Chem. Soc. 1995, 117, 1455-1456. doi:10.1021/ja00109a041

42. Wang, T.-Z.; Pinard, E.; Paquette, L. A. J. Am. Chem. Soc. 1996, 118, 1309-1318. doi:10.1021/ja9533609

43. Wu, X.; Zhou, J.; Snider, B. B. Angew. Chem., Int. Ed. 2009, 48, 1283-1286. doi:10.1002/anie.200805488

44. Foucher, V.; Guizzardi, B.; Groen, M. B.; Light, M.; Linclau, B. Org. Lett. 2010, 12, 680-683. doi:10.1021/ol902638w

45. Boyle, C. D.; Kishi, Y. Tetrahedron Lett. 1995, 36, 4579-4582. doi:10.1016/0040-4039(95)00852-4

46. Shi, Y.; Peng, L. F.; Kishi, Y. J. Org. Chem. 1997, 62, 5666-5667. doi:10.1021/jo9711347

47. Hartl, M.; Humpf, H.-U. J. Org. Chem. 2001, 66, 3678-3681. doi:10.1021/jo0000630

48. Hailes, H. C.; Isaac, B.; Javaid, M. H. Tetrahedron Lett. 2001, 42 , 7325-7328. doi:10.1016/S0040-4039(01)01437-X

49. Hanessian, S.; Mainetti, E.; Lecomte, F. Org. Lett. 2006, 8, 4047-4049. doi:10.1021/ol0615230

50. Xiao, Q.; Jackson, J. J.; Basak, A.; Bowler, J. M.; Miller, B. G.; Zakarian, A. Nat. Chem. 2013, 5, 410-416. doi:10.1038/nchem.1597

51. Hanessian, S.; Andreotti, D.; Gomtsyan, A. J. Am. Chem. Soc. 1995, 117, 10393-10394. doi:10.1021/ja00146a029

52. Reissig, H.-U. Angew. Chem., Int. Ed. Engl. 1996, 35, 971-973. doi:10.1002/anie.199609711

53. Donaldson, W. A. Tetrahedron 2001, 57, 8589-8627. doi:10.1016/S0040-4020(01)00777-3

54. Lebel, H.; Marcoux, J.-F.; Molinaro, C.; Charette, A. B. Chem. Rev. 2003, 103, 977-1050. doi:10.1021/cr010007e

55. Chen, D. Y.-K.; Pouwer, R. H.; Richard, J.-A. Chem. Soc. Rev. 2012, 41, 4631-4642. doi:10.1039/c2cs35067j

56. Hanessian, S.; Cantin, L.-D.; Andreotti, D. J. Org. Chem. 1999, 64, 4893-4900. doi:10.1021/jo990302n

57. Marinozzi, M.; Pellicciari, R. Tetrahedron Lett. 2000, 41, 9125-9128. doi:10.1016/S0040-4039(00)01629-4

58. Clive, D. L. J.; Liu, D. J. Org. Chem. 2008, 73, 3078-3087. doi:10.1021/jo702635t
59. Hanessian, S.; Cantin, L.-D.; Roy, S.; Andreotti, D.; Gomtsyan, A. Tetrahedron Lett. 1997, 38, 1103-1106. doi:10.1016/S0040-4039(96)02518-X

60. Marinozzi, M.; Serpi, M.; Amori, L.; Diaz, M. G.; Costantino, G.; Meyer, U.; Flor, P. J.; Gasparini, F.; Heckendorn, R.; Kuhn, R.; Giorgi, G.; Hermit, M. B.; Thomsen, C.; Pellicciari, R. Bioorg. Med. Chem. 2007, 15, 3161-3170. doi:10.1016/j.bmc.2007.02.040

61. Amori, L.; Serpi, M.; Marinozzi, M.; Costantino, G.; Diaz, M. G.; Hermit, M. B.; Thomsen, C.; Pellicciari, R. Bioorg. Med. Chem. Lett. 2006, 16, 196-199. doi:10.1016/j.bmcl.2005.09.014

62. Hanessian, S.; Cantin, L.-D. Tetrahedron Lett. 2000, 41, 787-790. doi:10.1016/S0040-4039(99)02211-X

63. Hanessian, S.; Moitessier, N.; Cantin, L.-D. Tetrahedron 2001, 57, 6885-6900. doi:10.1016/S0040-4020(01)00641-X

64. Hanessian, S.; Bennani, Y. L.; Hervé, Y. Synlett 1993, 35-36. doi:10.1055/s-1993-22337

65. Stowell, M. H. B.; Ueland, J. M.; McClard, R. W. Tetrahedron Lett. 1990, 31, 3261-3262. doi:10.1016/S0040-4039(00)89038-3

66. Rogers, R. S. Tetrahedron Lett. 1992, 33, 7473-7474. doi:10.1016/S0040-4039(00)60798-0

67. Kinnear, A. M.; Perren, E. A. J. Chem. Soc. 1952, 3437-3445. doi:10.1039/jr9520003437 See for the synthesis of allylphosphonic acid dichloride.

68. Kotoris, C. C.; Wen, W.; Lough, A.; Taylor, S. D. J. Chem. Soc., Perkin Trans. 1 2000, 1271-1281. doi:10.1039/a908086d

69. Koeller, K. J.; Spilling, C. D. Tetrahedron Lett. 1991, 32, 6297-6300. doi:10.1016/0040-4039(91)80151-U

70. Blazis, V. J.; Koeller, K. J.; Spilling, C. D. Tetrahedron: Asymmetry 1994, 5, 499-502. doi:10.1016/0957-4166(94)80002-2

71. Blazis, V. J.; Koeller, K. J.; Spilling, C. D. J. Org. Chem. 1995, 60, 931-940. doi:10.1021/jo00109a025

72. Isono, K.; Asabi, K.; Suzuki, S. J. Am. Chem. Soc. 1969, 91 , 7490-7505. doi:10.1021/ja01054a045 And references cited therein.

73. Emmer, G. Tetrahedron 1992, 48, 7165-7172. doi:10.1016/S0040-4020(01)88257-0 See for a synthesis of the racemic unnatural $(E)$-polyoximic acid.

74. Sun, H. H.; McEnroe, F. J.; Fenical, W. J. Org. Chem. 1983, 48, 1903-1906. doi:10.1021/jo00159a025

75. Midland, S. L.; Wing, R. M.; Sims, J. J. J. Org. Chem. 1983, 48, 1906-1909. doi:10.1021/jo00159a026

76. Menys, V. C.; Durrington, P. N. Br. J. Pharmacol. 2003, 139, 881-882. doi:10.1038/sj.bjp.0705331

77. Kourounakis, A. P.; Katselou, M. G.; Matralis, A. N.; Ladopoulou, E. M.; Bavavea, E. Curr. Med. Chem. 2011, 18, 4418-4439. doi:10.2174/092986711797287557

78. Do, R.; Kiss, R. S.; Gaudet, D.; Engert, J. C. Clin. Genet. 2009, 75, 19-29. doi:10.1111/j.1399-0004.2008.01099.x

79. Bezuidenhout, S. C.; Gelderblom, W. C. A.; Gorst-Allman, C. P.; Horak, R. M.; Marasas, W. F. O.; Spiteller, G.; Vleggaar, R. J. Chem. Soc., Chem. Commun. 1988, 743-745. doi:10.1039/c39880000743

80. Gelderblom, W. C.; Jaskiewicz, K.; Marasas, W. F.; Thiel, P. G.; Horak, R. M.; Vleggaar, R.; Kriek, N. P. Appl. Environ. Microbiol. 1988, 54, 1806-1811.

81. Gelderblom, W. C. A.; Marasas, W. F. O.; Vleggaar, R.; Thiel, P. G.; Cawood, M. E. Mycopathologia 1992, 117, 11-16. doi:10.1007/BF00497273 
82. Scott, P. M. Int. J. Food Microbiol. 1993, 18, 257-270. doi:10.1016/0168-1605(93)90149-B

83. Scott, P. M. Food Addit. Contam., Part A 2012, 29, 242-248. doi:10.1080/19440049.2010.546000

84. Pereira, C. L.; Chen, Y.-H.; McDonald, F. E. J. Am. Chem. Soc. 2009, 131, 6066-6067. doi:10.1021/ja9009265

See for the total synthesis of fumonisin $B_{1}$.

85. Fisher, J. F.; Meroueh, S. O.; Mobashery, S. Chem. Rev. 2005, 105, 395-424. doi:10.1021/cr030102i

86. Drawz, S. M.; Bonomo, R. A. Clin. Microbiol. Rev. 2010, 23, 160-201. doi:10.1128/CMR.00037-09

87. Worthington, R. J.; Melander, C. J. Org. Chem. 2013, 78, 4207-4213. doi:10.1021/jo400236f And references cited therein.

88. El-Gamal, M. I.; Oh, C.-H. Curr. Top. Med. Chem. 2010, 10, 1882-1897. doi:10.2174/156802610793176639

89. Papp-Wallace, K. M.; Endimiani, A.; Taracila, M. A.; Bonomo, R. A. Antimicrob. Agents Chemother. 2011, 55, 4943-4960. doi:10.1128/AAC.00296-11

90. McKenna, M. Nature 2013, 499, 394-396. doi:10.1038/499394a

91. Lewis, K. Nat. Rev. Drug Discovery 2013, 12, 371-387. doi:10.1038/nrd3975

92. Sader, H. S.; Gales, A. C. Drugs 2001, 61, 553-564. doi:10.2165/00003495-200161050-00001

93. Perboni, S.; Tamburini, B.; Rossi, T.; Donati, D.; Tarzia, G.; Gaviraghi, G. In Recent Advances in the Chemistry of Anti-infective Agents; Bentley, H. H.; Ponsford, R., Eds.; The Royal Society of Chemistry, T. Graham House: Cambridge, 1992; p 21.

94. Hanessian, S.; Reddy, G. B. Bioorg. Med. Chem. Lett. 1994, 4, 2285-2290. doi:10.1016/0960-894X(94)85026-7

95. Hanessian, S.; Rozema, M. J.; Reddy, G. B.; Braganza, J. F. Bioorg. Med. Chem. Lett. 1995, 5, 2535-2540. doi:10.1016/0960-894X(95)00445-Y

96. Hanessian, S.; Rozema, M. J. J. Am. Chem. Soc. 1996, 118, 9884-9891. doi:10.1021/ja962006n

97. Hanessian, S.; Griffin, A. M.; Rozema, M. J. Bioorg. Med. Chem. Lett. 1997, 7, 1857-1862. doi:10.1016/S0960-894X(97)00326-0

98. Zheng, G.-C.; Hatano, M.; Ishitsuka, M. O.; Kusumi, T.; Kakisawa, H. Tetrahedron Lett. 1990, 31, 2617-2618. doi:10.1016/0040-4039(90)80140-H

99. Zheng, G.-C.; Ichikawa, A.; Ishitsuka, M. O.; Kusumi, T.; Yamamoto, H.; Kakisawa, H. J. Org. Chem. 1990, 55, 3677-3679. doi:10.1021/jo00298a060

100.Kende, A. S.; Mendoza, J. S. Tetrahedron Lett. 1990, 31, 7105-7108 doi:10.1016/S0040-4039(00)97252-6

101.Blakemore, P. R. J. Chem. Soc., Perkin Trans. 1 2002, 2563-2585. doi:10.1039/b208078h

102.Dumeunier, R.; Markó, I. E. The Julia Reaction. In Modern Carbonyl Olefination; Takeda, T., Ed.; Wiley-VCH: Weinheim, 2004; pp 104-150.

103.McMurry, J. E.; Bosch, G. K. J. Org. Chem. 1987, 52, 4885-4893. doi:10.1021/jo00231a012

104.Ihara, M.; Taniguchi, T.; Tokunaga, Y.; Fukumoto, K. J. Org. Chem. 1994, 59, 8092-8100. doi:10.1021/jo00105a028

105.Zhang, Z.-Y. Annu. Rev. Pharmacol. Toxicol. 2002, 42, 209-234. doi:10.1146/annurev.pharmtox.42.083001.144616

106. Tonks, N. K. Nat. Rev. Mol. Cell Biol. 2006, 7, 833-846. doi:10.1038/nrm2039
107.Zato, S. W. Insulin and drugs used to treat diabetes. In Foye's Principles of Medicinal Chemistry, 7th ed.; Lemke, T. L.; Williams, D. A., Eds.; Lippincott Williams \& Wilkins, 2013; pp 877-906.

108. Rotella, D. P. J. Med. Chem. 2004, 47, 4111-4112. doi:10.1021/jm030626a

109. van Huijsduijnen, R. H.; Sauer, W. H. B.; Bombrun, A.; Swinnen, D. J. Med. Chem. 2004, 47, 4142-4146. doi:10.1021/jm030629n

110.Barr, A. J. Future Med. Chem. 2010, 2, 1563-1576. doi:10.4155/fmc. 10.241

111.Burke, T. R., Jr. Curr. Top. Med. Chem. 2006, 6, 1465-1471. doi:10.2174/156802606777951091

112.Birkedal-Hansen, H.; Moore, W. G. I.; Bodden, M. K.; Windsor, L. J.; Birkedal-Hansen, B.; DeCarlo, A.; Engler, J. A. Crit. Rev. Oral Biol. Med. 1993, 4, 197-250.

113. Nagase, H.; Visse, R.; Murphy, G. Cardiovasc. Res. 2006, 69, 562-573. doi:10.1016/j.cardiores.2005.12.002

114.Cheong, J.-J.; Choi, Y. D. Trends Genet. 2003, 19, 409-413. doi:10.1016/S0168-9525(03)00138-0

115.Büchi, G.; Egger, B. J. Org. Chem. 1971, 36, 2021-2023. doi:10.1021/jo00813a045

116. Tanahashi, T.; Takenaka, Y.; Nagakura, N.; Nishi, T. Chem. Pharm. Bull. 2000, 48, 1200-1204. doi:10.1248/cpb.48.1200 And references cited therein.

117. Tanahashi, T.; Takenaka, Y.; Nagakura, N.; Nishi, T. J. Nat. Prod. 1999, 62, 1311-1315. doi:10.1021/np9901175

118. Takenaka, Y.; Tanahashi, H.; Taguchi, H.; Nagakura, N.; Nishi, T. Chem. Pharm. Bull. 2002, 50, 384-389. doi:10.1248/cpb.50.384

119.Dhimitruka, I.; SantaLucia, J., Jr. Org. Lett. 2006, 8, 47-50. doi:10.1021/ol0524048

120. Inanaga, J.; Hirata, K.; Saeki, H.; Katsuki, T.; Yamaguchi, M. Bull. Chem. Soc. Jpn. 1979, 52, 1989-1993. doi:10.1246/bcsj.52.1989

121. Niswender, C. N.; Conn, P. J. Annu. Rev. Pharmacol. Toxicol. 2010, 50, 295-322. doi:10.1146/annurev.pharmtox.011008.145533

122.Amalric, M.; Lopez, S.; Goudet, C.; Fisone, G.; Battaglia, G.; Nicoletti, F.; Pin, J.-P.; Acher, F. C. Neuropharmacology 2013, 66, 53-64. doi:10.1016/j.neuropharm.2012.05.026

123. Attwell, P. J. E.; Kent, N. S.; Jane, D. E.; Croucher, M. J.; Bradford, H. F. Brain Res. 1998, 805, 138-143. doi:10.1016/S0006-8993(98)00698-2

124.Pellicciari, R.; Marinozzi, M.; Natalini, B.; Costantino, G.; Luneia, R.; Giorgi, G.; Moroni, F.; Thomsen, C. J. Med. Chem. 1996, 39, 2259-2269. doi:10.1021/jm960059+

125.Stierle, A. A.; Stierle, D. B.; Kelly, K. J. Org. Chem. 2006, 71, 5357-5360. doi:10.1021/jo060018d

126. McLeod, M. C.; Wilson, Z. E.; Brimble, M. A. J. Org. Chem. 2012, 77, 400-416. doi:10.1021/jo201988m

127.Fañanás, F. J.; Mendoza, A.; Arto, T.; Temelli, B.; Rodriguez, F. Angew. Chem., Int. Ed. 2012, 51, 4930-4933. doi:10.1002/anie.201109076

128. Wenderski, T. A.; Marsini, M. A.; Pettus, T. R. R. Org. Lett. 2011, 13, 118-121. doi:10.1021/ol102652t

129. McLeod, M. C.; Wilson, Z. E.; Brimble, M. A. Org. Lett. 2011, 13, 5382-5385. doi:10.1021/ol202265g

130.Snaddon, T. N.; Buchgraber, P.; Schulthoff, S.; Wirtz, C.; Mynott, R.; Fürstner, A. Chem.-Eur. J. 2010, 16, 12133-12140. doi:10.1002/chem.201001133

131.Bender, C. F.; Yoshimoto, F. K.; Paradise, C. L.; De Brabander, J. K. J. Am. Chem. Soc. 2009, 131, 11350-11352. doi:10.1021/ja905387r 
132. Buchgraber, P.; Snaddon, T. N.; Wirtz, C.; Mynott, R.; Goddard, R.; Fürstner, A. Angew. Chem., Int. Ed. 2008, 47, 8450-8454. doi:10.1002/anie.200803339

133. Reichenbach, H.; Höfle, G.; Gerth, K.; Washausen, P. PCT Int. Appl. WO97/31912, 1997.

134.Gerth, K.; Washausen, P.; Höfle, G.; Irschik, H.; Reichenbach, H. J. Antibiot. 1996, 49, 71-75. doi:10.7164/antibiotics.49.71

135.Connor, D. T.; Greenough, R. C.; von Strandtmann, M. J. Org. Chem. 1977, 42, 3664-3669. doi:10.1021/jo00443a006

136.Ringel, S. M.; Greenough, R. C.; Roemer, S.; Connor, D.; Gutt, A. L.; Blair, B.; Kanter, G.; von Strandmann, M. J. Antibiot. 1977, 30, 371-375. doi:10.7164/antibiotics.30.371

137. Höfle, G.; Steinmetz, H.; Gerth, K.; Reichenbach, H. Liebigs Ann. Chem. 1991, 941-945. doi:10.1002/jlac.1991199101161

138. Wenzel, S. C.; Müller, R. Nat. Prod. Rep. 2007, 24, 1211-1224. doi:10.1039/b706416k

139.Julien, B.; Tian, Z.-Q.; Reid, R.; Reeves, C. D. Chem. Biol. 2006, 13, 1277-1286. doi:10.1016/j.chembiol.2006.10.004

140. Michelet, V.; Genêt, J.-P. Curr. Org. Chem. 2005, 9, 405-418. doi: $10.2174 / 1385272053174903$ See for a review on ambruticin.

141. Hanessian, S.; Focken, T.; Oza, R. Tetrahedron 2011, 67, 9870-9884. doi:10.1016/j.tet.2011.09.069

142.Lee, E.; Choi, S. J.; Kim, H.; Han, H. O.; Kim, Y. K.; Min, S. J.; Son, S. H.; Lim, S. M.; Jang, W. S. Angew. Chem., Int. Ed. 2002, 41, 176-178.

doi:10.1002/1521-3773(20020104)41:1<176::AID-ANIE176>3.0.CO;2\#

143.Pospíšil, J.; Markó, I. E. J. Am. Chem. Soc. 2007, 129, 3516-3517. doi:10.1021/ja0691728

See for the total synthesis of the related jerangolid $D$.

144.Pospíšil, J.; Markó, I. E. Tetrahedron Lett. 2008, 49, 1523-1526. doi:10.1016/j.tetlet.2007.12.113

145. Ohira, S. Synth. Commun. 1989, 19, 561-564. doi:10.1080/00397918908050700

146. Müller, S.; Liepold, B.; Roth, G. J.; Bestmann, H. J. Synlett 1996, 521-522. doi:10.1055/s-1996-5474

147.Liu, P.; Jacobsen, E. N. J. Am. Chem. Soc. 2001, 123, 10772-10773. doi:10.1021/ja016893s

148.Kende, A. S.; Fujii, Y.; Mendoza, J. S. J. Am. Chem. Soc. 1990, 112, 9645-9646. doi:10.1021/ja00182a037

149. Kende, A. S.; Mendoza, J. S.; Fujii, Y. Tetrahedron 1993, 49, 8015-8038. doi:10.1016/S0040-4020(01)88025-X

150.Kirkland, T. A.; Colucci, J.; Geraci, L. S.; Marx, M. A.; Schneider, M.; Kaelin, D. E., Jr.; Martin, S. F. J. Am. Chem. Soc. 2001, 123, 12432-12433. doi:10.1021/ja011867f

151.Berberich, S. M.; Cherney, R. J.; Colucci, J.; Courillon, C.; Geraci, L. S.; Kirkland, T. A.; Marx, M. A.; Schneider, M. F.; Martin, S. F. Tetrahedron 2003, 59, 6819-6832. doi:10.1016/S0040-4020(03)00370-3

152. National Center for Biotechnology Information. PubChem Compound Database; $C I D=5870$. http://pubchem.ncbi.nlm.nih.gov/summary/summary.cgi?cid=5870 (accessed Feb 10, 2014).

153. Chapelon, A.-S.; Moraléda, D.; Rodriguez, R.; Ollivier, C.; Santelli, M. Tetrahedron 2007, 63, 11511-11616. doi:10.1016/j.tet.2007.08.087

154. Hanson, J. R. Nat. Prod. Rep. 2010, 27, 887-899. doi:10.1039/c001262a

155. Hu, Q.-Y.; Rege, P. D.; Corey, E. J. J. Am. Chem. Soc. 2004, 126, 5984-5986. doi:10.1021/ja048808x
156.Pattenden, G.; Gonzalez, M. A.; McCulloch, S.; Walter, A.; Woodhead, S. J. Proc. Natl. Acad. Sci. U. S. A. 2004, 101, 12024-12029. doi:10.1073/pnas.0401925101

157. Cai, Z. Y.; Covey, D. F. Steroids 2007, 72, 351-359. doi:10.1016/j.steroids.2006.12.007

158.Yeung, Y.-Y.; Chein, R.-J.; Corey, E. J. J. Am. Chem. Soc. 2007, 129, 10346-10347. doi:10.1021/ja0742434

159. Hakuba, H.; Kitagaki, S.; Mukai, C. Tetrahedron 2007, 63, 12639-12645. doi:10.1016/j.tet.2007.10.008

160.Soorukam, D.; Knochel, P. Org. Lett. 2007, 9, 1021-1023. doi:10.1021/ol063052n

161.Canales, E.; Corey, E. J. Org. Lett. 2008, 10, 3271-3273. doi:10.1021/ol8011502

162. Herrmann, P.; Buděšinský, M.; Kotora, M. J. Org. Chem. 2008, 73, 6202-6206. doi:10.1021/jo800620d

163.Xue, Y.-P.; Li, W.-D. Z. J. Org. Chem. 2011, 76, 57-64. doi:10.1021/jo1015486

164.Dietz, C.; Jouikov, V.; Jurkshat, K. Organometallics 2013, 32 , 5906-5917. doi:10.1021/om4004797

165. Hanessian, S.; Leblanc, Y.; Lavallée, P. Tetrahedron Lett. 1982, 23 , 4411-4414. doi:10.1016/S0040-4039(00)85615-4

166. Chauvin, A.-S.; Alexakis, A. Beilstein J. Org. Chem. 2006, 2, No. 6. doi:10.1186/1860-5397-2-6

167. Mastranzo, V. M.; Quintero, L.; de Parrodi, C. A. Chirality 2007, 19, 503-507. doi:10.1002/chir.20406

\section{License and Terms}

This is an Open Access article under the terms of the Creative Commons Attribution License (http://creativecommons.org/licenses/by/2.0), which permits unrestricted use, distribution, and reproduction in any medium, provided the original work is properly cited.

The license is subject to the Beilstein Journal of Organic Chemistry terms and conditions:

(http://www.beilstein-journals.org/bjoc)

The definitive version of this article is the electronic one which can be found at: $\underline{\text { doi:10.3762/bjoc. } 10.195}$ 